\title{
WestVirginiaUniversity
}

THE RESEARCH REPOSITORY @ WVU

Graduate Theses, Dissertations, and Problem Reports

2012

\section{Dating Anxiety and Paternal Dating Rules}

Chad S. Brice

West Virginia University

Follow this and additional works at: https://researchrepository.wvu.edu/etd

\section{Recommended Citation}

Brice, Chad S., "Dating Anxiety and Paternal Dating Rules" (2012). Graduate Theses, Dissertations, and Problem Reports. 103.

https://researchrepository.wvu.edu/etd/103

This Dissertation is protected by copyright and/or related rights. It has been brought to you by the The Research Repository @ WVU with permission from the rights-holder(s). You are free to use this Dissertation in any way that is permitted by the copyright and related rights legislation that applies to your use. For other uses you must obtain permission from the rights-holder(s) directly, unless additional rights are indicated by a Creative Commons license in the record and/ or on the work itself. This Dissertation has been accepted for inclusion in WVU Graduate Theses, Dissertations, and Problem Reports collection by an authorized administrator of The Research Repository @ WVU.

For more information, please contact researchrepository@mail.wvu.edu. 
Dating Anxiety and Paternal Dating Rules

Chad S. Brice, M.S.

Dissertation submitted to The Eberly College of Arts and Sciences at West Virginia University

in partial fulfillment of the requirements for the degree of

Doctorate of Philosophy

in

Psychology

Tracy L. Morris, Ph.D., Chair

Elisa Krackow, Ph.D.

Aaron Metzger, Ph.D.

Kristin Moilanen, Ph.D.

JoNell Strough, Ph.D.

Department of Psychology

Morgantown, West Virginia

2012

Keywords: Dating Anxiety, Parenting, Rules 


\section{ABSTRACT \\ Dating Anxiety and Paternal Dating Rules}

\section{Chad Brice, M.S.}

Dating anxiety is a specific type of social anxiety individuals experience in the presence of dating partners or potential dating partners that disrupts typical romantic development during adolescence. The etiological factors that contribute to dating anxiety have been less researched than other presentations of anxiety so the present research aimed to further explore potential contributors based on etiological factors related to other anxiety disorders. Many parent variables have been associated with anxiety disorders including parental anxiety, overcontrol, and fear-conditioning. In regard to dating, fathers have been shown to be more controlling and restrictive than mothers in their rule use. The present study aimed to examine the relation between adolescents' experience of dating anxiety and paternal involvement in adolescent dating relationships, specifically examining paternal concern about their adolescent dating, restrictive control over dating, and fear-conditioning through rules implemented specifically for safety. To assess adolescents experience of parental rules regarding dating, this study used a father-adolescent dyadic discussion task in which fathers presented rules for dating and then the dyad discussed the rules. Although paternal concern, restrictive rule use, and safety rationales presented during the dyadic discussion were not related to dating anxiety, aspects of the father-teen relationship and paternal involvement were related to dating anxiety. Adolescents' reports of negative interactions with their father were related to higher levels of dating anxiety. Also, paternal use of dating restriction as a consequence for rule violations were related to higher levels of dating anxiety. These finding suggest that the fatherteen relationship and restrictive control through restrictive consequences is important in adolescent romantic development. This study provides a research paradigm for further examining parental involvement in adolescent dating and dating anxiety, and offers targets for future research including ways to improve sample selection and observational tasks. 


\section{ACKNOWLEDGEMENTS}

First, I would like to thank my family and friends for their support and patience throughout this process. I would like to specifically thank my advisor, Dr. Tracy Morris, Ph.D., for her guidance and direction on this project and throughout my graduate career. A special thanks goes to Brian Creasy and Amanda Costello for their professional contributions to the research process. I would also like to honor the generosity and bravery of the fathers and adolescents who made this project possible. 


\section{TABLE OF CONTENTS}

TITLE PAGE

TABLE OF CONTENTS

PARENTAL CONTROL

PARTICIPANTS

MEASURES

PROCEDURE

RESULTS

DISCUSSION 
LIMITATIONS AND FUTURE DIRECTIONS 33

$\begin{array}{ll}\text { REFERENCES } & 42\end{array}$

$\begin{array}{ll}\text { TABLES } & 48\end{array}$

$\begin{array}{lr}\text { APPENDICES } & 60\end{array}$

$\begin{array}{ll}\text { CURRICULUM VITA } & 71\end{array}$ 
LIST OF TABLES

TABLE 1: CONTINUOUS DEMOGRAPHIC VARIABLES BY GENDER

TABLE 2: CATEGORICAL DEMOGRAPHIC VARIABLES BY GENDER

TABLE 3: INTERCODER RELIABILITY FOR WRITTEN RULES AND DATING RULES DISCUSSION TASK

TABLE 4: GENDER DIFFERENCES ON PATERNAL VARIABLES

TABLE 5: DATING STATUS DIFFERENCES BASED ON AGE, DAS-A SCORES, SPAI SCORES

TABLE 6: PATERNAL PREDICTORS OF DAS-A TOTAL SCORES

TABLE 7: CORRELATIONS AMONG PATERNAL PARENTING VARIABLES ASSOCIATED WITH DATING ANXIETY

TABLE 8: POSTHOD PATERNAL PREDICTORS OF DAS-A TOTAL SCORES

TABLE 9: GENDER INTERACTIONS FOR PATERNAL PREDICTORS OF DAS-A TOTAL SCORES 


\section{LIST OF APPENDICES}

APPENDIX A: DATING QUESTIONNAIRE

APPENDIX B: PARENTAL INVOLVEMENT IN ADOLESCENT ROMANTIC

RELATIONSHIPS: REVISED 


\section{Dating Anxiety and Paternal Dating Rules}

Dating is a rite of passage for Western adolescents. Among adolescents, the topography of dating varies depending on the adolescent's particular social context. Adolescents may be involved in a committed romantic relationship and not define the interpersonal interaction as dating, while another couple may communicate only through social media and consider this activity dating. For the purposes of this study, dating is considered any activity that involves an adolescent having or pursuing a romantic relationship. Romantic relationships have been broadly defined as voluntary relationships that involve some level of attraction that may or may not have a sexual component (Brown, Feiring, \& Furman, 1999). It is during these early romantic relationships that adolescents learn how to foster and maintain healthy romantic relationships throughout their lives. Being involved in romantic relationships throughout adolescence is predictive of having a more bonded romantic relationship in young adulthood (SeiffgeKrenke, 2003). When examining parental, peer and adolescent romantic relationships in relation to romantic relationship quality in young adulthood (ages 20-21), romantic relationship quality at age 16 was more predictive of romantic relationship quality in young adulthood over parent and peer influences (Madsen \& Collins, 2011). Romantic relationship quality was measured through ratings of conflict resolution, shared positive affect, and the ability to balance one's own needs with the needs of a partner. In this model, early supportive care by the parent (attachment, support, responsivity), and peer competence were no longer significant predictors of relationship quality in young adulthood, but a variable quantifying parent-child processes remained as a unique predictor. Parent-child processes included a willingness to express individual ideas freely, ability of the parent-child dyad to meet task demands, emotional connectedness, and positive affect between parent and child. These findings suggest that early romantic relationships and interactions with parents are important predictors of later romantic relationship quality.

One obstacle that teenagers face in the pursuit and maintenance of romantic relationships is dating anxiety. Dating anxiety is a specific type of social anxiety characterized by worries or fears experienced in the presence of dating partners or potential dating partners (Glickman \& La Greca, 2004). 
While dating anxiety is not a clinical syndrome, it has been linked to disruptions in typical romantic development including a later onset of dating and less frequent dating than same-age peers through young adulthood (Larson, Taggart-Reedy, \& Wilson, 2001). Given the importance of adolescent romantic relationships for later romantic relationships, it behooves researchers to examine factors that contribute to more positive romantic relationships during adolescence. To my knowledge, very few studies have directly examined dating anxiety and factors that contribute to its development (Glickman \& La Greca, 2004; La Greca \& Mackey, 2007). This study aims to highlight what is known about dating anxiety and parenting variables related to adolescent romantic relationship development, and extend that knowledge base by examining parenting variables related to other child and adolescent presentations of anxiety in relation to dating anxiety. Specifically, this study examines paternal control, paternal anxiety, and the communication of threatening information in the context of adolescent dating.

\section{Typical Romantic Development during Adolescence}

In order to understand the role that dating anxiety plays in adolescent romantic development, it is important to understand the typical trajectory of adolescent dating patterns. Brown (1999) proposed a sequence of normal dating development that occurs in four stages including an initiation phase, a status phase, an affection phase, and a bonded phase. These phases are defined by the function dating serves for the individual and how it contributes to romantic development. To examine these phases in relation to chronological ages Seiffge-Krenke (2003) examined when these developmental changes typically begin. The initiation phase (circa ages 11-13) involves young adolescents becoming comfortable interacting with the opposite sex (in heterosexual adolescents) and dating situations, but does not necessarily involve being involved in dating or romantic relationships. The status phase (circa ages 13-15) is best characterized by adolescents engaging in more stereotypical dating behaviors, but choosing dating partners based on the status of their partner and influences from their peers. By the time adolescents reach the affection phase (circa age 17), they are more likely to choose their partner based on their own attraction and values, and relationships become more intimate. The final, bonded phase (circa age 21) is 
when an individual's partner becomes their primary source of social support with increases in intimacy and connectedness.

Healthy romantic development helps adolescents identify and adaptively utilize sources of social support throughout their lives. Adolescents transition from relying more heavily on their parents, to relying on their peers, and finally relying primarily on their romantic partners. During late adolescence, romantic relationships become the most important source of social support for the adolescent (Furman \& Buhrmester, 1992). Early dating experiences influence adolescents' development through these transitions and can change the sources from which young adults receive social support. Adolescents who date earlier have been shown to rely more on their romantic partner for social support, while individuals who were not in romantic relationships at ages 13 and 15 relied more heavily on their parents and peers at age 21 (Seiffge-Krenke, 2003). Therefore, delays in romantic development associated with adolescent dating anxiety could be related to adolescents having difficulty developing autonomy from parents and building stronger romantic relationships in young adulthood.

\section{Dating Anxiety}

Although dating anxiety has been associated with delays in romantic development, some levels of dating anxiety are normative. In a study of high school students between the ages of 15 and 18 in grades ten through twelve, tenth graders reported more dating anxiety than eleventh or twelfth graders (Glickman \& La Greca, 2004). In relation to Brown's proposed developmental phases, adolescents typically would have less dating anxiety by the time they reach the affection phase of romantic development. These findings suggest that dating anxiety is more normative in early adolescence, but adolescents who continue to experience high levels of dating anxiety later in adolescence are more likely to have more trouble in romantic relationships than their peers. Specifically, adolescents who experience ongoing dating anxiety would have difficulty during the phase of romantic development when romantic relationships become more meaningful.

Dating anxiety has been less researched than other domains of anxiety such that the contributing and maintaining factors are not as well understood. Many of the features are similar to social phobia in 
that the anxiety is directly related to social situations. Unsurprisingly, findings related to dating anxiety often involve interpersonal relationships and limited exposure to potential dating partners. For example, high school students who had more friends of the opposite-sex were less likely to report dating anxiety than students who reported few or no friends of the opposite sex (La Greca \& Mackey, 2007). While this interpretation ignores potential differences for homosexual adolescents, this finding implies that adolescents report less dating anxiety if they are more comfortable with the desired sex. Additionally, adolescents who had never been in a romantic relationship or were not currently in a romantic relationship reported higher levels of dating anxiety than adolescents who had been in romantic relationships or reported being in a current dating relationship. Given the importance of social contact, it is possible that these findings would be better explained by social anxiety and related avoidance, but dating anxiety scores were found to be a better predictor of dating status than social anxiety scores (La Greca \& Mackey, 2007). The impact on dating experience gives support to examining dating anxiety as a specific type of social anxiety.

Limited exposure to potential dating partners was not the only significant predictor of dating anxiety La Greca and Mackey (2007) reported. Higher dating anxiety scores were also related to more negative interactions with a dating partner, which consisted of ratings of conflict, criticism, exclusion, dominance, and pressure. One potential explanation for the relation between dating anxiety and negative interactions with a dating partner can be borrowed from the social anxiety literature. Social skills have been found to mediate the role between social anxiety and peer acceptance (Greco \& Morris, 2005). While some negative romantic interactions could be attributed to partner variables such as having an aggressive partner, adolescents who are unaware of how to behave in dating relationships may feel anxiety about their real or perceived inadequacies. Real inadequacies could result in the adolescent engaging in behaviors that alienate or offend their partners through violations of dating scripts such as not reciprocating expressions of affection. Perceived inadequacies could simply create avoidance or inhibitions on the part of an anxious adolescent that result in perceived slights by a partner. Either way, these behaviors could lead to negative interactions associated with dating anxiety. 
Parental contributions to dating anxiety are even less understood than exposure to potential dating partners and may even serve as a preceding contributing mechanism. Using retrospective reports from college students, dysfunctional family rules have been associated with dating anxiety, less relational satisfaction, slower advancement through dating stages, and less commitment as reported later in young adulthood (Larson, Taggart-Reedy, \& Wilson, 2001). Larson et al. defined dysfunctional family rules as being associated with maladaptive family functioning and shame (e.g. "Don't identify, talk about, or solve problems"; or "Rather than be who you are, be good, right, strong, or perfect"). Larson et al.'s operationalization of family rules is more reflective of general parenting styles than specific parenting rules. This more general approach makes it difficult to determine which specific parenting rules contributed most strongly to dating anxiety. Parental rule use and related dating anxiety could be part of the parent-child process associated with romantic relationship quality in young adulthood (Madsen \& Collins, 2011). Assessing specific parenting variables relevant to dating may elucidate what types of parental involvement in adolescent dating is associated with adolescent dating anxiety.

\section{Parent-Child Relationship and Dating}

Peer and parental relationships have been shown to be important to the presentation of adolescent dating anxiety. Although dating anxiety usually decreases with age (Glickman \& La Greca, 2004), a more thorough examination of the parent-child relationship may reveal ways that parental involvement influences adolescents going through this transition. Examining parenting variables that contribute to other forms of anxiety can help guide research to identify parental contributions to dating anxiety. Concurrently exploring parenting variables associated with adolescent romantic outcomes can inform directions for combining research about adolescent anxiety and adolescent romantic relationships to better understand adolescent dating anxiety.

Many findings suggest that positive parent-child relationships and interactions predict later positive romantic relationships and interactions. For example, a reliable alliance between adolescents and parents at ages 15 and 16 is predictive of connectedness and attraction with a romantic partner in early adulthood (Seffge-Krenke, Shulman, \& Klessinger, 2001). Attachment to parents determines the way that 
adolescents interact with romantic partners (Collins \& Sroufe, 1999; Gray \& Steinberg, 1999; Hazan \& Shaver, 1987; Hazan \& Shaver, 1994). Using an attachment perspective in which the relationship to the parent functions as the prototype for other interpersonal interactions, Roisman, Madsen, Hennighausen, Sroufe, and Collins (2001) found that the parent-child process during interactions at age 13 was related to the romantic relationship process when the adolescent was 20 years old. The dyadic processes described by Roisman et al. were based on several variables observed during dyadic coding. The parent-child process was defined by willingness to express individual ideas freely, positive affect, emotional connectedness, and the ability to complete a task, while the romantic relationship process included a willingness to express individual ideas freely, ability to mutually resolve conflicts, degree to which the relationship helps personal development, shared positive affect, ability to seek or provide care in a timely manner, and overall relationship quality. These findings suggest that further examination of the parentchild relationship could further illuminate some of the early predictors of dating anxiety and subsequent delays in romantic development.

Many of the features of parent-child relationships associated with more positive romantic outcomes are also related to lower levels of anxiety. Using a hierarchical regression, Anhalt and Morris (2008) demonstrated that criticism and care made significant contributions to higher ratings of anxiety among college students, with criticism being associated with higher levels of anxiety and care being associated with lower anxiety levels. Given the parallels between dating anxiety and other types of anxiety, one might expect criticism and level of care to be associated with dating anxiety as well. For example, positive parent-child relationships in which there is a significant level of care might be associated with less dating anxiety. Similarly, less parental criticism of adolescent romantic relationships should be related to less dating anxiety and more positive romantic relationships.

There are many ways that parents may influence their offspring's romantic development directly or indirectly. For example, interparental conflict is directly related to conflict in adolescent romantic relationships and is moderated by adolescents' perceptions of interparental conflict (Simon \& Furman, 2010). Specifically, adolescents engaged in more conflict in in their own romantic relationships if they 
perceived interparental conflict as being threatening or their own fault. Additionally, young adults' level of intimacy with their romantic partner can be predicted by family cohesion in their family-of-origin and maternal marital satisfaction (Feldman, Gowen, \& Fisher, 1998). This may be a result of adolescents learning how to behave in their own romantic relationships through the way that their parents model romantic interactions. Adolescents may also use the parent-child relationship to obtain interpersonal skills that prove useful in their later romantic relationships either through practice, instruction, or consultation. Parental psychopathology has also been associated with childhood anxiety diagnoses (Messer \& Beidel, 1994). Although childhood anxiety symptoms may be inherited genetically, it is possible that parents model anxious or avoidant coping strategies. These strategies may generalize to dating situations such that parental anxiety about adolescent dating may result in more dating anxiety for adolescents.

\section{Parental Control}

Parental control of adolescent dating behavior may also be associated with dating anxiety. Parental control has been frequently linked to child anxiety in the form of overcontrol and lack of autonomy-granting (Siqueland, Kendall, \& Steinberg, 1996). Mothers and fathers of children diagnosed with generalized anxiety disorder, separation anxiety disorder, or social phobia have been observed as granting less autonomy on structured tasks than parents of children without anxiety disorders (Siqueland et al., 1986). It is likely that adolescents who experience more dating anxiety also have parents who grant less autonomy in their adolescents' dating relationships. These findings suggest that more control of adolescent dating may contribute to the development and maintenance of dating anxiety.

Parents control adolescent behavior by using rules and applying consequences for adolescent behavior. Parental reactions to adolescent behavior, the way those responses are presented, and the rationales they provide for their adolescent largely determine the way that adolescents perceive and respond to parental control (Padilla-Walker \& Carlo, 2004). Findings from Padilla-Walker and Carlo (2004) are in regard to responses parents gave for more general adolescent antisocial and prosocial behaviors, but are indicative of dyadic experiences between parents and adolescents in regard to parental control. Adolescents were more likely to perceive their parents' rules as appropriate if adolescents 
perceived the intention of the rule as being helpful and caring instead of controlling. Adolescents were also more likely to experience anger if parents yelled or used punishment instead of talking to the adolescent about the behavior which was associated with adolescents experiencing happiness when adolescent had been engaging in prosocial behavior, and guilt when the adolescent engaged in antisocial behavior. While these findings are not in relation to adolescent dating, they emphasize the importance the consequences parents utilize in response to adolescent behavior.

There are some differences between mothers and fathers in the way that they control adolescent behaviors. In examining general parental responses to adolescent behavior, fathers were more likely to be perceived as punitive and restricting than mothers (Padilla-Walker \& Carlo, 2004). Fathers also have been shown to be more controlling of their children with an anxiety disorder than their children who do not have an anxiety disorder (Barrett, Fox, \& Farrell, 2005; Greco \& Morris, 2002). Furthermore, mothers are more likely to be supportive of romantic relationships, while fathers are more restrictive (Kan, McHale, \& Crouter, 2008). In comparison to mothers, fathers have received far less attention with respect to parental influence on the development of psychopathology including anxiety, but are more controlling in the studies that do include fathers (Bogels \& Phares, 2007). If parental control is important in developing or maintaining dating anxiety, including fathers is important to accurately assess the level of control that adolescents experience from their parents.

\section{Dating-Specific Rules}

The way that parents control adolescent romantic relationships may differ slightly from the way that they control other adolescent behaviors, therefore it is important to review how parents control adolescent dating behaviors. Some research regarding parenting and adolescent romantic relationships mix constructs related to control and support such that their results also reflected more general parenting styles than specific behaviors. For example, Kan et al. (2008) analyzed data about parental support, concerns, restriction, and autonomy granting. Three types of parental involvement were identified as negatively involved, positively involved, and autonomy oriented. Negatively involved parents were defined as having high levels of concern and restriction, and low levels of support and autonomy. 
Positively involved parents were defined as having low levels of concern and restriction, high levels of support, and a moderate amount of autonomy. Autonomy-oriented parents granted high levels of autonomy, provided a moderate amount of support, and expressed low levels of concern and restriction. No specific parenting style was universally related to the primary outcome variables of adolescent romantic competence and intimacy with romantic partners. Findings did suggest a goodness-of-fit between parenting styles and time spent with mothers. For example, adolescents whose parents were negatively involved scored higher on romantic competence and intimacy if they spent more rather than less time with their mothers. Conversely, offspring of positively involved parents were more romantically competent if they spent less time with their mothers. Additionally, offspring of autonomy-oriented parents rated themselves as higher in romantic intimacy if they spent less time with their mothers. Some dyadic interactions such as conflict or some other feature of parent-child processes predictive of romantic relationship quality in young adulthood (Madsen \& Collins, 2011) may explain the differences in romantic competence and intimacy based on parenting styles and time spent with mothers. Analyzing parent-child processes related to dating may also illuminate dyadic features that contribute to dating anxiety.

Just as dating-specific anxiety is more predictive of dating behaviors than more general social anxiety (La Greca \& Mackey, 2007), examining dating-specific rules may elucidate the ways that parenting approaches affect dating anxiety. Madsen (2008) provides a framework for examining dating rules based on function by categorizing each rule as a supervision, restriction, or prescription rule. Supervision rules involve the parents being aware of the adolescent's dating, including meeting the adolescent's boyfriend/girlfriend, and knowing where they are going. Restriction rules limit the adolescent's behavior with rules like "no kissing" or curfews. Prescription rules were instructions for how the adolescent should behave while dating and included rules like "Open the car door for her."

Use of these rule types is related to constructs already associated with adolescent romantic outcomes. The use of supervision rules was associated with higher quality parent-child relationships, but was not predictive of adolescent romantic relationship quality. Madsen (2008) only examined adolescent 
romantic relationship outcomes at one time point, so it is possible that positive outcomes related to supervision rule use are not readily apparent in that sample. Parents who used more supervision rules also were more comfortable with their secure base role as a parent simultaneously setting rules and fostering autonomy. The use of supervision rules bodes well for the parent and the parent-child relationship without having a negative impact on the adolescent's romantic relationship. If the parent-child relationship serves as a model and training ground for further interpersonal relationships and supervision rules are associated with better parent-child relationships, then the use of more supervision rules could be predictive of better romantic relationships when adolescents reach adulthood.

Restriction and prescription rules were not associated with positive outcomes for the parent-child relationship or the adolescent's romantic relationship. Adolescents whose parents used more restriction rules or prescription rules were more likely to perceive their fathers as psychologically controlling (Madsen, 2008). The construct of psychological control is very similar to the control associated with childhood anxiety (Siqueland et al., 1986). Restriction rules were more likely to be used if adolescents were in romantic relationships at the time of the study. Logically, this makes sense because parents do not need to have rules to restrict behaviors in which the adolescent is not likely to engage. Restriction rules were also the most controlling of the rule types proposed by Madsen (2008).

\section{Fear Conditioning and Anxiety}

In considering rule use, rationales for the rules could be important when considering anxiety because the amount of negative or threatening information that parents use can increase the likelihood of dating anxiety or fear beliefs about dating situations. Field and colleagues have been programmatically exploring how information presented to children affects fear and avoidance in effort to demonstrate how anxiety can be socialized (Field, Ball, Kawyez, \& Moore, 2007; Field \& Lawson, 2003; Field, Lawson, \& Banerjee, 2008; Field, \& Storksen-Coulsen, 2007; Lawson, Banerjee, \& Field, 2007). Field presented children with positive, negative, or neutral information about marsupial animals with which the children were unlikely to have any experience. Children who received the negative information about the marsupial from researchers reported more fear and avoidance in relation to the unknown marsupial than 
children who received neutral or positive information (Field, 2003). The process of evoking fear and avoidance based on presenting information is considered fear conditioning (Field, 2003). When the parent-child relationship was examined, a punitive maternal parenting style and more negative paternal interactions were associated with children having higher levels of fear beliefs about the novel animal (Field, 2007). The fear conditioning to the novel animal is also resistant to changes over time in that children continued to display fear and avoidance of the marsupial at a six-month follow up (Field et al., 2008).

Fear conditioning in regard to social situations has been more difficult because children have more experience with and information about social situations than novel animals (Lawson et al., 2007). Lawson et al. presented young adolescents with positive, negative, and neutral information about social situations and stated that the information came from parents, older children, and same age peers. Interestingly, negative information always produced an increase in fear beliefs about the social situation and there were no differences in the strength of the change in fear beliefs based on the source of the information. Unlike information about social situations presented in research studies, much of a child's first exposure to information about social situations comes from their parents, therefore it is possible that parents condition fear based on the information they provide.

In addition to control, paternal overprotection has been associated with child anxiety disorders. Fathers who had an anxious child reported being more overprotective in general than fathers who did not have an anxious child (Hudson \& Rapee, 2005). Parents of anxious children may have a disposition to overprotect because they are more likely to perceive threats (Silverman, Cerny, Nelles, \& Burke, 1988). Parents are likely to communicate their own fears to their children either directly or indirectly. In dating situations, parents can produce fears that are both realistic and unrealistic. Parental use of scare tactics or threatening information in their rationales for dating rules may lead to dating anxiety and subsequent avoidance of situations in which adolescents develop the skills necessary to maintain a romantic relationship. 


\section{Adolescent Sexual Behavior}

It is important to clarify that parental concerns, protection and control serve a function for adolescent romantic development, but they should be balanced with autonomy. One major domain where parents attempt to maintain control is adolescent sexual behavior. Parental control of sexual behavior can be very difficult when adolescents are struggling to obtain more autonomy. Some control can be useful considering adolescents who perceived their parents as very strict were less likely to engage in sexual behaviors than adolescents who saw their parents as having very few rules about sexual behaviors (Miller, McCoy, Olson, \& Wallace, 1986). However, adolescents who saw their parents as very strict had more premarital sexual attitude permissiveness (values indicating that premarital sex is acceptable) than adolescents who saw their parents as slightly less strict. Similarly, fathers who reported the most rules had daughters who reported higher premarital sexual attitude permissiveness than fathers who reported slightly fewer rules. These results emphasize the need to balance autonomy and control when making rules about sexual behaviors because the sexual attitude permissiveness in the strictest of families was still not as high as the families that had no or very few rules, but more than families that had a moderate number of rules. These specific findings about rules about sexual behaviors emphasize the need to balance control and autonomy for positive romantic development.

The ways that parents attempt to control sexual behavior through promoting abstinence from sex, use of protective measures (e.g. condoms), or limiting the number of sexual partners are also related to adolescent sexual risk-taking (Parkes, Henderson, Wight, \& Nixon, 2011). In that investigation, parental values restricting adolescents from engaging in sexual activity was related to delays in adolescents initiating intercourse, but was not related to condom use among adolescents who did engage in sexual activity. Furthermore, Parkes and colleagues (2001) also revealed that parental monitoring of adolescent behavior was associated with delayed onset of intercourse and higher rates of condom use. While restriction serves its intended function of delaying the onset of sexual intercourse, monitoring adolescents served the same function as well as an increase in condom use. These findings suggest that supervision 
rules will be as useful as, if not more useful than restriction rules in limiting risky sexual behaviors among adolescents.

Conversely, the frequency of parental communication their values about contraception use was negatively related to delays in adolescents' first experience with intercourse (Parkes et al., 2011). In fact, the frequency with which parents communicate the risks associated with sexual behaviors is associated with lower levels of condom use and a greater likelihood for adolescents to initiate sexual activity (Deptula, Henry, \& Schoeny, 2010). Despite the fact that threat communications are not related to lower levels of sexual risk-taking, parents are more likely to support public service messages that portray sexual behaviors as risky or threatening (Tanner, Carlson, Raymond, \& Hopkins, 2008). These findings suggest that parents limiting threatening communications about dating will not necessarily serve to increase sexual risk-taking, but might actually decrease dating anxiety along with sexual risk-taking behaviors.

\section{Gender Differences}

There are some gender differences in the way that parents treat their adolescents and in how adolescents respond to rules. Both mothers and fathers are more likely to be more restrictive with daughters and allowing sons more autonomy (Kan et al., 2008). Interestingly, longitudinal evidence suggests that there is a gender difference in the need for autonomy with females forming more romantic intimacy if their parents had greater respect for privacy and flexible family control, while males had more trouble with romantic intimacy under these circumstances (Feldman, Gowen, \& Fisher, 1998). It is possible that there is a gender interaction between dating anxiety and parental restriction.

Kan et al. (2008) found that parent-child conflict led to different outcomes for male and female adolescents depending on parenting style. Conflict with autonomy-oriented fathers had differing effects on male and female adolescents' romantic intimacy. Females developed more romantic intimacy if they had less conflict with their fathers, while males developed more romantic intimacy if they had more conflict with their fathers. It is possible that girls are more susceptible to outcomes associated with parentchild conflict, as further evidenced by boys being more likely to express indifference about their parents' control of their behavior (Padilla-Walker \& Carlo, 2004). 


\section{Statement of Purpose}

The goal of this study was to examine the association among parenting style, parental rules and information about dating, and adolescent dating anxiety. Many features of the parent-child relationship have been associated with other domains of anxiety including parental anxiety, overprotection, and fearconditioning. This study specifically examined the father-adolescent dyad because fathers have been identified as being more restrictive in regard to adolescent dating and are therefore more likely to utilize control in regard to their adolescent dating. A metanalytic review of studies examining parental control in relation to childhood anxiety yielded higher effect sizes for this relation in studies that included a discussion task (Bruggen, Bogels, \& Stams, 2008). Therefore, this study utilized an observation of dyadic discussions to assess for the way that adolescents experience paternal dating rules and how they impact adolescent dating behaviors and anxiety. The general hypothesis for this study was that higher levels of parenting variables related to anxiety in children also would be predictive of higher levels of dating anxiety in adolescents. Three paternal features were explicitly expected to be positively related to dating anxiety and those include paternal anxiety, paternal control, and fear-conditioning. Given that dating anxiety is a very specific behavioral presentation, these features were examined as specifically related to adolescent dating. Paternal anxiety was examined through paternal concern about adolescent dating behavior. Paternal control was measured by fathers' use of restriction rules in order to limit adolescent dating. Fear-conditioning was measured through fathers' use of rationales indicating that their rules were used to keep the adolescent safe.

\section{Method}

\section{Participants}

Participants were 60 high school students (30 male and 30 female) between the ages of 14 and 18, and their cohabitating father figures. Participants were recruited through schools, community organizations, word-of-mouth, and responding to posted fliers. The mean participant age was 15.25 years with a standard deviation of 1.14 years. The median and modal age was 15 years. Continuous demographic variables are presented in Table 1. Participants identified as being $81.7 \%$ white, $13.3 \%$ 
Black, 3.3\% Native American, and 1.7\% biracial. Categorical demographic variables are presented in Table 2. All participants identified as being heterosexual. Participants were categorized as being active daters, inactive daters or non-daters. Of the 60 participants, $45 \%$ identified as active daters $(n=27 ; 11$ male, 16 female), $36.7 \%$ identified as inactive daters ( $n=22 ; 14$ male, 8 female), and $18.3 \%$ identified as non-daters $(n=11 ; 5$ male, 6 female). Active daters had an average of $4.42(S D=3.68)$ dating partners in their lifetime as compared to inactive daters who had an average of $3.59(S D=2.28)$ lifetime dating partners. Active daters reported an average length of their longest dating relationship to be 9.58 months $(S D=8.59)$, while inactive daters reported an average longest relationship of 6.33 months $(S D=4.45)$.

Father figures were biological fathers $(78.3 \%, n=47)$, stepfathers $(10 \%, n=6)$, grandfathers $(5 \%$, $n=3)$, adoptive fathers $(3.3 \%, n=2)$, an uncle $(1.7 \%, n=1)$, and a mother's fiancé $(1.7 \%, n=1)$. The mean and modal age of father figures was 49 years $(S D=8.69)$ with a range of 27 to 80 years of age with the youngest two father figures being stepfathers and oldest three father figures being biological grandfathers. The age range for biological fathers was from 36 to 62 years of age. Father figures were 81.7\% White $(n=49), 11.7 \%$ Black $(n=7), 5 \%$ Native American $(n=5)$, and $1.7 \%$ biracial $(n=1)$.

Two participants (one male and one female) were excluded from analyses involving the Dating Anxiety Scale for Adolescents (DAS-A) due to omitting more than $40 \%$ of the items. Despite prompts to respond to items hypothetically, these individuals stated that the questionnaire items were not applicable to them. One other male participant's data for the Dating Rules Discussion Task was excluded due to an error in the audio recording.

\section{Measures}

\section{Adolescent self-report measures.}

Dating Anxiety Scale for Adolescents (DAS-A). The DAS-A (Glickman \& La Greca, 2004) is a 26-item questionnaire used to assess adolescents' anxiety in heterosocial and dating situations. Items are rated on a 5-point scale ranging from 1 (not at all characteristic of me) to 5 (extremely characteristic of $m e$ ). There are 5 positively stated filler items to avoid stigma related to questionnaire items. Factor analysis revealed three subscales (Glickman \& La Greca, 2004). Fear of Negative Evaluation-Dating 
(FNE-Dating; 10 items) reflects concern or worry that a date or a member of the other sex would judge the adolescent in a negative manner (e.g., "I am usually worried about what kind of impression I make while on a date"); Social Distress-Dating (SAD-Date; 7 items) reflects inhibition and distress while interacting with a member of the other sex on a date or socially (e.g., "I feel nervous in dating situations."'); and Social Distress-Group (SAD-Group; 4 items) reflects inhibition and distress during heterosocial group situations (e.g., "I often feel nervous or tense in casual get-togethers in which both guys and girls are present.'”). The DAS-A and the subscales had good internal consistency in this study: .95 for Total DAS-A, .92 for FNE-Dating, .86 for SAD-Date, and .75 for SAD-Group. In a previous investigation, a confirmatory factor analysis revealed a very good fit for the three-factor model of the three subscales (Glickman \& La Greca, 2004). The DAS-A was also shown to be a better predictor of dating status than social anxiety ratings (Glickman \& La Greca, 2004).

Network of Relationships Inventory (NRI). The NRI (Furman \& Buhrmester, 1985) provides comparisons across relationships and was used to compare adolescents' reports of their relationships with their father, mother, same-sex best friend, opposite-sex best friend, and romantic partner if applicable. The NRI has been used for many purposes including examining peer relationships, parent-child relationships, and dating relationships. The NRI consists of 45 items that comprise 15 scales of 3 items each. Participants rate each item on a five-point scale ranging from 1 (little or none) to 5 (the most). Social Support and Negative Interchanges factors are currently derived from 14 of the 15 scales (Furman, personal communication, May 13, 2009). Previously there were 12 scales that consisted of 7 social provisions that made up the Social Support scale which included Reliable Alliance, Enhancement of Worth, Instrumental Help, Affection, Companionship, Intimacy, and Nurturance; three scales assessing Negative Interchanges including Conflict, Punishment, and Annoyance; and two additional scales assessing Relative Power Status, and Satisfaction with the Relationship. The Social Support and Negative Interchanges factors have excellent internal consistency (Connolly \& Konarski, 1992). The original 12 scales have satisfactory internal consistency (Furman \&Buhrmester, 1985; Furman \& Buhrmester, 1992). Currently, the Social Support factor is determined by averaging the scores from the 
Companionship, Instrumental Aid, Intimacy, Nurturance, Affection, Admiration, Reliable Alliance, Satisfaction, and Support subscales. The Negative Interchanges factor is determined by averaging the scores on the Conflict, Antagonism, Criticism, Dominance, and Punishment scales. Relative Power is the only scale that is not included in the Social Support or Negative Interaction factor. Separate scores on each scale were obtained for each relationship examined. Internal consistency was good for both the father-adolescent Social Support scale (.95) and Negative Interchanges scale (.92). Internal was satisfactory for the father-adolescent subscales (Companionship $=.75$, Conflict $=.84$, Instrumental Aid $=.83$, Antagonism $=.82$, Intimacy $=.85$, Nurturance $=.64$, Affection $=.90$, Admiration $=.72$, Relative Power $=.71$, Reliable Alliance $=.84$, Support $=.89$, Criticism $=.86$, Dominance $=.84$, Satisfaction $=.92$, Punishment $=.82$ ).

Dating Questionnaire (Appendix A). Adolescents were asked about their relationship status, dating history, and sexual history. Dating status was coded according to the categories established by Kuttler, La Greca, and Prinstein (1999) which include (a) Active Dater (is currently in a relationship), (b) Inactive Dater (has been in a relationship but is not currently), (c) Non-Dater (has not been in a dating relationship). Adolescents were asked, "Have you ever been on a date or had a boyfriend/girlfriend?" If adolescents responded "no", then they were considered non-daters. If adolescents indicated that they had been on a date, or had a boyfriend or girlfriend, then they were asked whether they were currently in a relationship. Adolescents who indicated, "yes" to this question were considered active daters, while adolescents who indicated "no" were considered inactive daters. Active daters were asked whether they are in a committed relationship. Dating history included the number of lifetime dating relationships, length of longest relationship, age of first relationship, a list of dating activities (e.g., going to the movies), and whether dates are alone or in a group. Sexual history included number of partners, types of sexual experiences (e.g., sexual intercourse, oral sex, manual sexual behaviors), use of protection, and age of first sexual experience. 


\section{Paternal self-report measures.}

\section{Parental Involvement in Adolescent Romantic Relationships - Revised (PIARR-R; Appendix B).}

The PIARR (Kan, McHale, \& Crouter, 2008) was developed to determine parental Supportive

Involvement, Restrictive Involvement and Autonomy-Granting in adolescent romantic relationships.

Fathers rated items on a 4-point scale from 1 (strongly disagree) to 4 (strongly agree). Kan et al. adapted this measure based on measures of parental management of adolescents' peers from Mounts (2001) and Updegraff et al. (2001). Additionally, Kan et al. added a scale for Parental Concerns about dating because parents are only able to be involved in adolescent dating behaviors of which they are aware. In this sample, the internal consistency for paternal ratings on all four scales was good (Concern $=.90$, Supportive Involvement $=.81$, Restrictive Involvement $=.73$, Autonomy $=.84$ ). Two items assessing parental concern and acceptance about their offspring being homosexual were included for this study because parental control may be specifically related to this issue. One item assessed for parental concern about their child being homosexual and the second item assessed for how accepting fathers would be if their child were homosexual.

Parental Rules, Rationale, and Consequences (Appendix C). Similar to Madsen (2008), fathers were asked to list any dating rules they had for the adolescent. In addition to listing rules, fathers were asked to include the rationale for each rule and the consequences if the adolescent broke the rule. Some categories, such as natural consequences, were added to accommodate rationales and consequences with a high base rate that were previously absent from the proposed coding system, while other categories were combined due to low base rates and similar functions, such as combining previously proposed categories of protecting familial interests and protecting academic interests into a global category of protecting other interests. The total number of each type of rule, rationale, and consequence were tallied separately. Inteerrater reliability scores were assessed by calculating weighted Cohen's kappa $(k w)$ using MedCalc software and interpreted using guidelines described by Landis and Koch (1977). Rules were coded as (a) Supervision $(k w=.88)$, (b) Restriction $(k w=.78)$, or (c) Prescription $(k w=.83)$, rules according to Madsen's coding system. The total number of written rules ranged from 0 to 10 with an average of 3.38 
rules $(S D=2.01)$. Fathers used an average of .80 supervision rules $(S D=1.02), 1.62$ restriction rules $(S D=1.12)$, and .95 prescription rules $(S D=1.33)$

Rationales were coded as either (a) preventing Sexual Behaviors $(k w=.75)$, (b) promoting Healthy Romantic Relationships $(k w=.83)$, (c) Safety $(k w=1.0)$, (d) protective of Other Interests (e.g. school, family, sports, friendships) $(k w=1.0(\mathrm{e})$, protective of the adolescent's integrity $(k w=1.0)$ a need to Control or Monitor the adolescent's behavior $(k w=1.0)$, or (f) having an Unspecified Rationale $(k=$ 1.0). Each rule was coded as having at least one rationale. Additionally, each rationale category explicitly mentioned in regard to a rule was coded for that rule; however, no single rationale category was coded twice for a single rule. For example, a curfew imposed for a teenager's safety and to ensure rest for the following day at school (protecting Other Interests) would be coded for Safety and protective of Other Interests, but if a limit is put on dating time to ensure that a child has time for homework and time to spend with family then protecting Other Interests would only be coded once. This allowed the data to reflect the separate functions for a rule without inflating a single rationale type. Fathers used an average of .45 sex rationales $(S D=.70), .27$ healthy relationship rationales $(S D=.55), .90$ safety rationales $(S D$ $=1.23), .42$ other interests rationales $(S D=.62), 1.38$ control rationales $(S D=1.39)$, and .38 integrity rationales $(S D=.77)$, and .25 unspecified rationales $(S D=.68)$.

Consequences were coded as (a) Verbal (e.g. a lecture or yelling) $(k w=1.0$, (b) punishment or Loss of Privileges (e.g. grounding or extra chores) $(k w=.60)$, (c) Dating Restrictions $(k w=.51)$, (d) Natural Consequences (unwanted pregnancy) $(k w=1.0)$, or (e) No Consequences specified $(k w=.84)$. Similar to rationales, each rule was coded as having at least one consequence and each separate consequence type for each rule was coded once. For example, if a violation resulted in dating restrictions and loss of cell phone use then both Dating Restriction and Loss of Privileges would be coded, but if the teenager was grounded and loss cell phone privileges without dating restrictions being specified, then Loss of Privileges would be coded only once. Fathers used a mean of .13 verbal consequences $(S D=.39)$, 1.00 restriction consequences $(S D=1.48), .47$ natural consequences $(S D=1.08)$, and .40 unspecified consequences (SD .76). 
The overall Degree of Control $(k w=.21)$ was coded for each set of dating rules using a 5-point scale reported by Madsen (2008). This code was utilized to assess for how reasonable or controlling an overall set of rules was, beyond the number and type of rules used. The lowest rating (1) was reserved for a lack of rules and general permissiveness. A (2) was given to sets of rules that were permissive with only minimal rules that did not limit dating opportunities (e.g. sets of rules that only consisted of a single rule such as a curfew or mild supervision). A (3) was given to sets of rules that imposed moderate control over the adolescent's dating behavior without restricting the adolescents ability to date. For example, a moderate amount of supervision and restriction rules that only limited aspects of dating such as dating partner age or prohibiting unprotected sex. Higher degree of control ratings were given for sets of rules that limited an adolescent's dating opportunities. Sets of rules that limited dating opportunities such as partner selection characteristics, early curfews, or high levels of supervision were given a rating of (4). Finally, sets of rules that were extremely prohibitive such as restricting all dating or requiring circumstances for dating that were unlikely to be satisfied were given the highest Degree of Control rating (5). Coding rubrics and examples can be found in Appendix D.

\section{Observational measures.}

Dating Rules Discussion. - Using the rules, rationales, and consequences fathers provided, they were asked to discuss their dating rules with their adolescent. This task was utilized to determine how fathers present their rules for dating to the adolescent, as it is more likely to reflect the way that adolescents experience their father's rules. It was hypothesized that the impact that these rules have on adolescents' dating behavior would be more related to the fathers' verbal presentation than their written rules that would only be conveyed to the researchers. Conversations were videotaped. Paternal verbal behavior was coded according to the same criteria as their written responses (e.g. Degree of Control, rules, rationales, consequences). The following prompt was provided to the father and adolescent: “(Dad's name), using the rules that you wrote down earlier, present these rules one at a time to your adolescent and allow him/her to respond if they choose. You may choose to discuss the rule with your adolescent if you would like. Once you are finished discussing the first rule, move on to the second and so on. Continue 
to present the rules until I return. (Adolescent's name), you may respond to your father's (or fatherfigure's) rules but you are not required to respond. Please let him know when you are ready for the next rule. Are you both ready?"

Coding of dyadic discussions took place after the completion of data collection to reduce coding drift and to ensure that coding rubrics were sufficient to capture the data present in the discussions. Each video was transcribed to improve the accuracy of coding for content, but coding was done from the videos rather than transcripts to account for the tone of the content.

On the discussion task, fathers used an average of 3.80 rules $(S D=2.16)$, with an average of 1.02 supervision rules $(S D=1.22), 1.80$ restriction rules $(S D=1.28)$, and 1.02 prescription rules $(S D=1.21)$. Fathers gave a mean number of .49 sex rationales $(S D=.68), .38$ healthy relationship rationales $(S D$ $=.72), .68$ safety rationales $(S D=.97), .53$ other interests rationales $(S D=.73), 1.29$ control rationales $(S D=1.16), .44$ integrity rationales $(S D=.70)$, and .63 unspecified rationales $(S D=.95)$. Fathers gave a mean number of .12 verbal consequences $(S D=.38), 1.15$ restriction consequences $(S D=1.24), .73$ dating restriction consequences $(S D=1.32), .25$ natural consequences $(S D=.54)$, and 1.73 unspecified consequences $(S D=1.70)$.

Interrater reliability for rule usage was substantial to almost perfect for all rule types. Agreement for supervision rule usage $(k w=.89)$ on the discussion task was the same as for written supervision rules, but reliability for restriction rules $(k w=.62)$ and prescription rules $(k w=72)$ were slightly lower. Reliability for sex rationales was perfect $(k w=1.0)$, while safety $(k w=.70)$, other interests $(k w=.67)$, control $(k w=.69)$, healthy relationship $(k w=.84)$, and unclear rationales $(k w=.90)$ ranged from moderate to almost perfect. Coding for integrity rationales $(k w=.00)$ was poor and only detected by one coder in the sample of videos analyzed for reliability coding. Consequence coding was also less reliable for the dating rules discussion than for written rules. Moderate agreement was obtained for verbal consequences $(k w=.65)$ punishment or loss of privileges $(k w=.47)$, and natural consequences $(k w=.66)$. Dating restriction $(k w=.25)$ agreement was fair while no consequences $(k w=.09)$ only had very slight 
agreement. Interrater reliability for the degree of control in the discussion task was moderate $(k w=.43)$ and was more reliable than the written rules score.

We originally proposed the use of the Family Problem Solving Code (FAMPROS; Forbes, Vuchinich, \& Kneedler, 2001) to examine dyadic interactions. After data collection began, it became clear that this coding system would be inadequate to appropriately measure the unique dyadic features of the Dating Rules Discussion. The FAMPROS coding system was originally used for a task that required dyads to discuss an area of conflict. The FAMPROS codes Positive Behaviors and Negative Behaviors of each member of a discussion toward other group members, Participation, Relationship, and four problem solving codes. Positive behaviors include displays of affection, warmth, support and understanding. Negative behaviors include criticism, anger, disagreement, complaining, and rejection. Both Positive Behaviors and Negative Behaviors are rated on a 7-point scale ranging from 1 (virtually none) to 7 (very high). Varying lengths of the Dating Rules Discussion made standardization of these codes unreliable. Similarly the problem-solving codes (Definition of Problem, Extent of Resolutions, Quality of Proposed Solutions, and Problem Solving Process) were not applicable to the dating rules discussion. Finally, the Participation code is rated on a 7-point scale to identify families where one member dominates or one member is withdrawn or excluded. Even distributions indicate a democratic family process, and low overall Participation indicates low engagement or avoidance. Given the nature of the Dating Rules Discussion task, the conversations were primarily led by the father with the adolescent only having the opportunity to respond, which would also have limited the variability on this scale.

As a result of the FAMPROS coding system being inappropriate for the Dating Rules Discussion, a new set of observational codes were developed specifically for this task and coding rubrics can be found in Appendix D. Given the uniqueness of the rule discussion task, the new set of codes was developed after the completion of data collection to include variables that would account for dyadic features that would be directly related to the study objectives including anxiety and control. There was a wide range in the duration of discussion lengths $(0: 26-10: 24 ; M=3: 40, S D=2: 20)$, so observational variables were coded on an interval scale rather than variables accounting for frequency or duration of target 
variables. Father and adolescent behavior during the video were coded on a 5-point scale for Adolescent Discomfort or Anxiety, Paternal Discomfort or Anxiety, Adolescent Questioning and Challenging, Adolescent Engagement, Paternal Checking-in, and Paternal Rule Flexibility (Appendix D). Anchors for these codes were determined based on observable qualities noted in the videotaped discussions and every attempt was made to have scores follow a continuous scale reflective of the range of observed qualities during the dyadic discussion rather than categorical differences.

Both Adolescent and Paternal Discomfort and Anxiety scales were used to measure observable verbal and nonverbal markers of discomfort and anxiety during the discussion. Scores on both Discomfort and Anxiety scales ranged from no observable anxiety or discomfort being the lowest rating (1), to strong nonverbal and verbal discomfort and anxiety being the highest rating (5). Interrater reliability was moderate for adolescent discomfort $(k w=.50)$ and fair for paternal discomfort $(k w=.38)$. Adolescents and fathers received an average rating of $3.08(S D=1.34)$ and $2.03(S D=1.16)$ respectively for observed discomfort and anxiety.

Adolescent Questioning and Challenging was used to assess how much the adolescent challenged or accepted the set of rules the father presented. The lowest rating (1) indicated that the adolescent did not challenge or seek clarification on any of the rules. Intermediate scores range from seeking mild clarification (2) to multiple challenges to the rules (4). The highest rating (5) indicates that the adolescent outright refused to accept or comply with at least one of the stated rules. Intercoder reliability for adolescent questioning $(k w=.93)$ and challenging was almost perfect. Adolescents were coded as having an average score of $2.14(S D=1.46)$ on the questioning and challenging code.

Adolescent Engagement in the discussion was used to assess how much the adolescent was involved in the discussion with higher scores indicating more involvement. The lowest score was reserved for adolescents who showed no overt indications that they were engaging in the discussion. This includes no verbalization, minimal eye contact, and no nonverbal acknowledgements. Scores increased based on nonverbal indicators of paying attention and the adolescent making more meaningful contributions to the conversation. The highest score was reserved for discussions during which the adolescent used the 
discussion to discuss issues outside of the father's stated dating rules. Intercoder agreement for adolescent engagement $(k w=.48)$ was moderate. Adolescents were coded as having an average score of 3.44 (SD $=.97$ ) for engagement.

Paternal Checking-in is a measure of how often and to what extent the father allows and encourages the adolescent to participate in the discussion of the rules. The lowest rating (1) was reserved for fathers who did not ask a single question during the task, and ended the task without the adolescent contributing to the discussion. Intermediate scores were determined based on the frequency of the father checking-in with the adolescent and whether the father used open or close-ended questions. High ratings were given to more frequent checking-in and the use of open-ended questions. The highest rating was reserved for fathers who required the adolescent to give an in-depth response to a question or prompt. Intercoder scores were fair for paternal checking in $(k w=.28)$. Fathers were coded as having an average score of $3.27(S D=1.40)$ for checking in.

Paternal Rule Flexibility is a measure of how willing the father was to change a rule when in response to resistance from the adolescent. This measure was the observed variable most susceptible to categorical differences in paternal behavior. Many discussions did not include any portrayal of flexibility and the ability for fathers to demonstrate flexibility was often related to whether the adolescent challenged the rules presented. The lowest rating (1) indicates that the father outright refuses to consider changing a rule. A moderate rating (3) indicates that the father is willing to consider changing a rule. A willingness to change a rule when challenged was coded as a (4). In circumstances when fathers were not challenged, the highest rating (5) was given when fathers offered to be flexible in regard to a rule without being challenged. A low rating (2) was given to fathers who were not challenged and did not indicate any intent to be flexible in regard to dating rules. This intermediate score was determined because this presentation does not indicate flexibility or inflexibility. It could be argued that these fathers could fall anywhere on the continuum of flexibility and should be excluded from these analyses. After all of the videos were coded, $66 \%(n=39)$ of fathers received a score of 2 for not having any mention of flexibility in the discussion. Excluding these participants would result in insufficient sample power to analyze this 
variable. There were no significant differences between individuals who did not demonstrate any discussion of flexibility and those who did on Dating Anxiety scores suggesting that this difference was not directly related to the primary outcome variable. Intercoder reliability for paternal flexibility $(k w=$ $1.0)$ with scores of 2 included was perfect. Fathers were coded as receiving an average score of 2.34 ( $S D$ $=1.11$ ) for flexibility.

\section{Procedure}

Participants were recruited through fliers, word-of-mouth, schools, or community groups and scheduled to participate either in their home, a private setting of their choosing, or laboratory at West Virginia University. Before beginning, a member of the research team conducted the informed consent and assent procedure with adolescents and their fathers. After participants signed the informed consent, the primary investigator or one other graduate student separated the father and adolescent to administer the following questionnaires: Dating Questionnaire; Network of Relationships Inventory; Dating Anxiety Scale for Adolescents; Parental Involvement in Adolescent Romantic Relationships; Paternal Rules for Dating, Rationales and Consequences. After completing the self-report questionnaires, adolescents and their fathers were reunited for the Dating Rules Discussion. The researcher read the Dating Rules Discussion prompt and each dyad was allowed to carry on the discussion for up to 15 minutes. Following the discussion, each dyad received $\$ 25$ for their participation in the study.

All written rule and dating rule discussion variables were analyzed for intercoder reliability by having two raters code $20 \%$ of the sample $(n=12)$ and conducting weighted kappa $(k w)$ analyses (Table 3). The principle investigator was considered the master coder and conducted training for one other graduate student coder in order to complete intercoder reliability analyses. Training was conducted on one day over approximately five hours and consisted of the master coder teaching the observational scales, presenting the trainee with multiple examples of written rules and videotapes, having the trainee practice coding rules and videos, and providing feedback. Videos were randomly selected for reliability coding prior to training to ensure that they were excluded from the training procedure. The principle investigator played five videos to model the coding procedure and to allow the second coder to ask questions about the 
codes in relation to the videos. The principle investigator then allowed the second coder to conduct coding autonomously but ask questions during approximately ten videos. Finally, the second coder rated videos autonomously and the principle trainer provided corrective feedback for approximately ten videos. Training was concluded when the trainee was able to code two videotapes consecutively without coding errors.

\section{Results}

Preliminary analyses were conducted to examine gender differences for variables related to adolescent dating (Dating Questionnaire), adolescent dating and social anxiety (DAS-A, SPAI), paternal dating rule use (Dating Rules, Rationales, and Consequences; Dating Rules Discussion), and paternal involvement in adolescent romantic relationships (PIARR-R). Sexual experiences were excluded from these initial gender analyses because only $16.7 \%$ of participants $(n=10)$ indicated that they had been sexually active. One-way Analyses of Variance (ANOVAs) did not indicate any significant gender differences between adolescent males and females for age of first dating experience, length of longest dating relationship, age of first kiss, DAS-A scores, or SPAI scores.

Gender differences emerged indicating that fathers were more protective of daughters in regard to dating. Significant gender differences are reported in Table 4. A one-way ANOVA revealed that fathers used more supervision rules with daughters $(M=1.53, S D=1.36)$ than sons $(M=0.48, S D=0.78), F(1$, $57)=16.28, p=.001$ during the discussion task, but not on the written rules. Also, fathers used more rationales for written rules indicating that daughters' dating behavior needed to be controlled or monitored $(M=1.77, S D=1.61)$ than for sons' $(M=1.00, S D=1.02), F(1,58)=4.853, p<.05$. The same finding persisted during the discussion task with daughters being given more rule rationales indicating that their behavior should be controlled or monitored $(M=1.60, S D=1.33)$, than sons $(M=$ 0.97, $S D=0.87), F(1,57)=4.69, p<.05$. Fathers scored higher on the PIARR-R Autonomy scale in regard to sons $(M=8.50, S D=1.59)$ as opposed to daughters $(M=7.53, S D=2.08), F(1,58)=4.09, p$ $=.048$. Fathers were more likely to provide rule rationales indicating that rules served to prevent sexual 
behaviors with sons $(M=0.69, S D=0.81)$ than daughters $(M=0.30, S D=0.47), F(1,57)=5.21, p<.05$ during the video task, but not on the written rules.

Preliminary analyses also were conducted to examine dating status in relation to age, DAS-A scores and SPAI scores and are presented in Table 5. There were no observed differences between nondaters, active daters and inactive daters in regard to DAS-A Total scores, any of the three DAS-A subscales, or the SPAI Total score. Although the mean age differences between active daters $(M=15.26$, $S D=0.98)$, inactive daters $(M=15.68, S D=1.25)$, and non-daters $(M=14.36, S D=0.47)$ were only approximately a year apart, active and inactive daters were significantly older than non-daters $F(2,57)=$ $5.63, p<.01$.

A multiple linear regression was used to determine the unique variance in adolescent dating anxiety explained by paternal restrictive control, threatening communications, and paternal anxiety about their adolescent dating (Presented in Table 6). In order to detect moderate effect sizes in this sample, only three variables could be examined. Each dyad has a score for Restriction Rules and Safety Rationales from both the written rules and the Dating Rules Discussion, and only one set of scores could to be chosen for this analysis. Discussion task variables were chosen over written rule variables because rules were often added during the discussion task that were not present in the written rules as evidenced by a higher average number of rules. The discussion task variables also represent how the rules are presented to the adolescent and therefore are more likely to reflect the way that these variables impact the adolescent's dating experience. Finally, discussion tasks revealed stronger effect effect sizes for the relation between control and child anxiety (Bruggen et. al, 2008). Restriction Rules were chose because they are a measure of restrictive control similar to parental overcontrol associated with child and adolescent anxiety. Safety Rationales were chosen because they are a way that parents communicate that dating may not be safe. The PIARR-R Parental Concern score was chosen because it is a measure of paternal anxiety about their adolescent dating that is not necessarily observable in the Dating Rules Discussion. All three variables were entered simultaneously into a multiple linear regression to predict DAS-A Total Scores. This model did not predict DAS-A Total scores and only predicted $6.1 \%$ of the 
variance $\left(R^{2}=.061, F(3,53)=1.15, p=.34\right)$. Neither Restriction Rules-Discussion $(\beta=.001, p=.995)$, nor Safety Rationales-Discussion $(\beta=4.19, p=.10)$, nor PIARR-R Parental Concern scores $(\beta=-.329, p$ $=.46)$ significantly predicted DAS-A Total scores.

Post-hoc analyses were conducted to determine associations between dating anxiety and additional study variables related to paternal control, paternal concern, and communications that dating could be threatening. Pearson correlations were conducted to examine DAS-A Total scores in relation to Dating Rules Discussion variables including rationales indicating that behavior should be Controlled or Monitored, Dating Restriction Consequences, Punishment or Removal of Privileges Consequences, Paternal Flexibility, Paternal Discomfort, and Paternal Checking-in. Written rule variables also were examined to determine whether there is a differential effect for what was preemptively determined by fathers and what was presented to the adolescents. Those written rule variables included Restriction Rules, Safety Rationales, Control and Monitoring Rationales, Dating Restriction Consequences, and Punishment or Removal of Privileges Consequences. Finally, the NRI Negative Interchanges with Father score was included to assess for the child's perception of the father-teen relationship. A correlation matrix is presented in Table 7. Three variables were significantly correlated with DAS-A Total scores including Safety Rationales-Written $(r=.28, p=.032)$, Dating Restriction Consequences-Written $(r=.36, p$ $=.006)$, and NRI Negative Interchanges-Father $(r=.30, p=.026)$. In each of these cases, higher levels of the variable related to higher levels of dating anxiety.

A second multiple linear regression was conducted with Safety Rationales-Written, Dating Restriction Consequences-Written, and NRI Negative Interchanges-Father entered simultaneously to predict DAS-A scores (Table 8 ). The model accounted for $24.6 \%$ of the variance in DAS-A scores $\left(\mathrm{R}^{2}\right.$ $=.246, \mathrm{~F}(3,53)=5.75, p=.002)$ with Dating Restriction Consequences $(\beta=.290, p=.025)$ and NRI Negative Interchanges with Father $(\beta=.273, p=.026)$ functioning as unique predictors with greater usage of restriction consequences and higher negative interchange ratings being related to higher levels of dating anxiety. 
Gender interactions were then examined between Dating Restriction Consequences and NRI Negative Interchanges and their impact on DAS-A scores (Table 9). Gender interaction dummy variables for both Dating Restriction Consequences and NRI Negative Interchanges were created in order to examine potential gender interactions. When Dating Restriction Consequences and NRI Negative Interchanges were entered with the Gender x Dating Restriction and Gender x NRI Negative Interchanges dummy variables, the model remained significant, $\left(\mathrm{R}^{2}=.498, \mathrm{~F}(4,52)=4.3, p<.01\right)$, but only Dating Restriction Consequences remained as a unique predictor $(\beta=.519, p<.01)$ indicating that no gender interactions were detected for either Dating Restriction Consequences or NRI Negative Interchanges with Fathers.

\section{Discussion}

This study attempted to identify paternal parenting variables that contribute to the development and maintenance of dating anxiety. It was hypothesized that three paternal factors related to presentations of childhood anxiety would be predictive of dating anxiety, including paternal anxiety, paternal control, and fear-conditioning. In order to measure these constructs in relation to dating anxiety specifically, they were measured using variables directly related to adolescent dating. First, paternal anxiety was measured using paternal concerns about their adolescent dating using a targeted questionnaire. Second, paternal use of rules that restricted their adolescent's ability to date was operationalized a measurement of prohibitive control specific to dating. Third, fear-conditioning was measured by fathers' use of rationales that their adolescent needed rules to keep them safe. These rationales provide information to the adolescent indicating that dating situations are unsafe or threatening in some way. None of these variables were predictive of dating anxiety in this sample, but other features of paternal rules for their adolescent dating, and the father-child relationship were related to adolescent dating anxiety. Specifically, negative interactions with their father and paternal use dating restriction consequences for adolescents violating dating rules, were positively related to dating anxiety.

This study advances the area of research related to adolescent dating anxiety by taking a domain specific approach to the subject of dating, dating anxiety, and related paternal parenting styles and rules. 
No other study has examined paternal involvement in adolescent romantic relationships directly in relation to adolescent dating anxiety. Findings from this study can inform professionals about parenting practices that contribute to dating anxiety, and guide future research into adolescent dating anxiety, in order to help produce more positive romantic outcomes later in life.

\section{Main Findings}

Based on previous findings linking parental control to child anxiety (Siqueland et al., 1986), it was expected that parental in regard to adolescent dating behavior would be related to higher levels of dating anxiety. However, paternal control in the form of fathers using restriction rules was not related to dating anxiety in this study. Restriction rules could be necessary for fathers to manage adolescents' behavior and therefore so generally applied that it is unclear what impact they have on dating anxiety. It is possible that restriction rules presented prior to dating can contribute to dating anxiety, while their use with adolescents who are more risk-taking in dating situations is more reactionary on the part of the parent. Another possibility is that fathers are perceived as the more controlling parent and therefore adolescents expect their use of restriction rules. An examination of maternal restriction rules may demonstrate their contribution to dating anxiety.

Although control in the form of restriction rules was not related to dating anxiety as initially proposed, this study was able to identify that control in the form of prohibiting dating after rule violations was related to dating anxiety. In this study, fathers produced consequences for their adolescent violating rules independent of whether the rule had ever been violated or there was a likelihood for the rule to be violated. This premeditated consequence of restricting access to dating could be a better indication of a father's propensity to control their adolescent's dating behavior, and therefore still indicate control as being related to dating anxiety. It is possible that in anxiogenic father-adolescent dyads, fathers attempt to grant autonomy to their adolescents in dating situations while reserving the right to restrict further access in the event that they become uncomfortable with the adolescent's behavior. The pressure adolescent feel in regard to meeting paternal expectations in order to maintain the freedom to date, and to meet expectations in dating relationships could produce ambivalence that leads to greater anxiety in 
dating situations.

Given that dating anxiety is associated with delays in the development of romantic relationships (Larson, Taggart-Reedy, \& Wilson, 2001) and early romantic relationship quality is predictive romantic relationship quality during young adulthood (Madsen \& Collins, 2011), it is important to make recommendations for parents to engage in parenting strategies that lead to more positive romantic outcomes. Dating restrictions for violating dating rules seems like a logical consequence for rule violations in that the consequence would directly relate to the offense. Findings from this study indicate that dating restrictions for adolescents violating dating rules would be contraindicated for minimizing dating anxiety. It is possible that there is a difference between adolescents anticipating these consequences without having violated any rules and adolescents receiving these consequences in response to rule violations. This is particularly important to note because much of this sample had not been involved in dating situations and these consequences were stated independent of adolescents violating rules. Adolescents also rated dating anxiety before being exposed to their father's rules, rationales or consequences. It is possible that a father's propensity to restrict dating opportunities is more related to dating anxiety than the actual use of the rule. Therefore, it is possible that these consequences are reasonable and effective ways to manage dating rule violations, but fathers should limit the ways that they communicate intentions or desires to limit dating opportunities.

It was hypothesized that paternal concern, a particular form of anxiety fathers experienced in relation to their adolescent dating, would be related to dating anxiety among adolescents. These predictions were based on higher levels of anxiety among fathers of anxious children (Messer \& Beidel, 1994). Results from this study did not support this hypothesis. It is possible that this variable was not related to adolescent dating anxiety for a number of reasons. This study measured paternal concern about adolescent dating in a questionnaire format that asked about a number of very specific concerns about adolescent dating. The intensity of these concerns was not directly measured by this questionnaire and therefore may not be reflected in the parental concern variable included in this study. This measure served a dual role in this study. First, it served to prompt fathers to consider potential ways in which they 
directly influence their adolescent dating before listing their dating rules. Second, it served as a measure of fathers' thoughts about their adolescent dating that may not be explicitly stated during the dating rules discussion due to anxiety, irrelevance to the adolescent's current dating status, forgetfulness, or some other limiting factor. This first function was not intentional but became apparent through paternal verbalizations during the discussion task. The Parental Involvement in Adolescent Romantic Relationship - Revised scale was chosen for the intentional purpose of measuring paternal anxiety because it was a validated measure with which adolescent romantic relationships had already been examined (Kan et al., 2008). In order to examine paternal anxiety about their adolescent dating more directly, another measure should be designed to cover more potential areas of concern with a greater range of potential responses for each item, to produce more statistical sensitivity to the variability of concerns between parents. These items could be developed by reviewing commonly reported rule rationales from this study, such as concerns about adolescent driver safety, or adolescents choosing partners of developmentally appropriate ages.

Paternal fear-conditioning in regard to adolescent dating was measured through the examination of rationales that fathers used indicating that their rules had the intention of keeping adolescents safe. These rationales have the potential for indicating that dating situations are not safe and that the adolescent therefore needs to be protected. Although safety rationales used during the dating rules discussion were not predictive of adolescent dating anxiety, written safety rationales were significantly correlated with dating anxiety. The use of safety rationales was not the most predictive parenting variable contributing to dating anxiety in the final post-hoc model, but the small sample size and resulting limited power of this study give support to examining this variable further in the future. It is noteworthy that written safety rationales were more directly associated with dating anxiety than safety rationales communicated during the dating rules discussion task. There was a lower average number of safety rationales used during the discussion task than presented in the written rules. It is possible that fathers expressed safety concerns in writing and did not bother repeating those concerns during the discussion with their adolescent. Fathers were not explicitly instructed to present rationales during the discussion in order to preserve the 
ecological validity of the task. Although the omission of rationales was not related to dating anxiety, the absence of rule rationales could have been related to dating anxiety and requiring their inclusion would have obscured this result. Now that omitted rationales have not been associated with dating anxiety, requiring their inclusion in future dating rule discussions could provide more information about how paternal rationales influence dating anxiety.

Adolescents' negative interactions with their fathers were related to higher levels of dating anxiety. This is consistent with finding about negative interactions with fathers predicting negative romantic outcomes. There are a number of subscales that contribute to the NRI negative interchanges score that could contribute to dating anxiety including conflict, punishment, and annoyance. Further examinations of these variables could inform directions for understanding the mechanisms through which father-teen dyadic variables are related to dating anxiety. The NRI subscales have a limited number of items, which make them a difficult means of exploring dating anxiety in relation to negative interactions adolescents have with their fathers. Given the finding that dating restriction consequences were also related to dating anxiety, it is likely that punishment is a consistent predictor of dating anxiety. Future studies should examine conflict and annoyance more directly in order to parse out their unique contributions to dating anxiety. Perhaps other tasks in which conflict and annoyance could be observed would be useful for examining these variables in relation to dating anxiety.

This study was able to replicate findings that fathers are more controlling of their daughters than their sons (Kan et al., 2008). Fathers used more supervision rules and rationales that their behavior needs to be controlled with their daughters, while granting sons more autonomy. These findings indicate that fathers believe that their daughters need to be controlled and supervised more than sons. The findings in this study produced potentially contradictory findings in that fathers provided more rules for the purpose of preventing sexual behaviors with sons than daughters. Perhaps fathers trust their sons less in regard to inhibiting sexual behavior and therefore provide more rules that serve to inhibit sexual behavior.

\section{Limitations and Future Directions}

This study was innovative in many ways and examined features of adolescent development that 
are less understood including dating anxiety and father-child relationships using an observational research design. Findings from this study and issues related to the design provide three directions for informing future research in regard to dating anxiety. Those areas include features of sample selection, areas of future research focus, and task design.

\section{Sample selection.}

One important limitation to this study is the constricted low age range of participants. Participants in this sample fall into the age range more typical of the status phase of romantic relationships. This is the beginning of a period when adolescents engage in dating for the explicit purpose of forming romantic relationships in order to gain status with approval from their peers (Brown, 1999). It is the phase just beyond building comfort in situations with potential dating partners. A follow-up with these participants when they are in later adolescence or young adulthood might display a more direct impact of dating anxiety on the development of romantic relationships, once their relationships have the potential to be fulfilling and meaningful. It is possible that the adolescents in this sample were in the midst of a critical period during which adolescents initiate dating relationships and findings are more related to typical development rather than the effects of dating anxiety. In other words, dating anxiety experienced by this sample would be normative, but similar levels of dating anxiety in late adolescence would be indicative of deviations from typical development.

Additionally, dating anxiety has previously been determined to be more normative in younger adolescents with more inhibited outcomes becoming apparent later in adolescence (Glickman \& La Greca, 2004). This sample included adolescents between the ages of 15 and 18 with a mean and modal age of 15 years, which places participants in the earlier stages of romantic development where dating anxiety is more normative. Therefore the potential negative outcomes of parenting factors contributing to dating anxiety may not be readily apparent in this sample. An older sample limited to adolescents around age 17 would be more likely to exhibit differential effects of parenting on dating anxiety because dating anxiety would not be as normative in this age range. During older adolescence is also when adolescents are more likely to rely on romantic partners for social support (Furman \& Buhrmester, 1992). A more 
thorough examination of sources of social support and dating anxiety may reveal impacts that dating anxiety may have on adolescents developing autonomy from their parents and forming closer relationships with romantic partners. The current sample is developmentally too young for that level of autonomy to be associated with positive outcomes.

Attempts were made to recruit older participants such as including the older of two siblings when there were two willing adolescents in the same household. In many cases, scheduling conflicts prevented older potential participants from inclusion. Fathers of these potential participants attributed scheduling conflicts to the adolescent being involved in other activities such as employment or extracurricular activities including dating activities. It is possible that an unintentional selection bias due to difficulties coordinating the schedules of the father, adolescent, and research staff prevented older and more active teenage daters from participating. Older adolescents who chose not to participate or had difficulty scheduling are potentially engaging in more typical behaviors associated with building autonomy and independence from their parents (Seiffge-Krenke, 2003). Additionally, selection biases are frequently suspect in anxiety research because of the avoidance that comes along with anxiety. For example, socially anxious adolescents report more avoidance and distress in social situations as they age which could include research participation (Sumter, Bokhorst, \& Westenberg, 2009). These concerns are amplified in examinations of social anxiety in that social situations such as being observed or judged are the feared stimuli. As a result of these two selection biases, this sample may include adolescents who are more moderate in both inhibition and autonomy.

In addition to potential selection biases that may exclude some adolescents, this study did not control for other participant variables that may mediate or moderate impacts of parenting on dating anxiety. Dating in adolescence is such a nuanced phenomena, many participant characteristics would have to be controlled in order to thoroughly understand how some variables relate to dating anxiety. Many features of the way that parents control adolescent behavior may have to do with dating status, sexual orientation, and family composition. This study recruited participants independent of these variables in order to examine dating anxiety as a continuous variable in all adolescents its relation to paternal dating 
rules. Statistically controlling for these variables requires a much larger sample size and reduces the ability to make recommendations that are readily useful for parents. Future studies should recruit participants based on dating status as this may directly influence whether parents have or enforce rules related to dating. The rules presented in this study may not be consistent with daily parenting practices and be more likely a reflection of paternal concerns in fathers of non-daters. Some information presented to adolescents prior to dating may be useful while other information may serve to create dating anxiety. That same information presented after the onset of dating may lead to more positive romantic outcomes for adolescents. For example, a father restricting a non-dating daughter from dating boys who ride motorcycles likely creates this rule out of anticipatory fear, while a father who applies the same rule to a daughter currently dating a boy who rides a motorcycle would be creating this rule based on a real threat.

The study sample is also limited in that only heterosexual teens participated in the investigation. This study did not intentionally exclude homosexual adolescents, but no adolescents in this sample identified as being homosexual. It is likely that data for homosexual adolescents would be different from heterosexual adolescents for a number of reasons. In the context of our culture, it is possible that dating anxiety would be higher for homosexual adolescents due to societal pressures, potential for ostracism, and parental disapproval. While trends are changing in our society, an equal number of fathers in this sample indicated that they would approve of their adolescent being homosexual as would not approve. Parental control of dating in homosexual adolescents may be very different and contribute more directly to dating anxiety.

\section{Relationships selected for research focus.}

The relationships examined in relation to dating anxiety are also important. This study focused on the father-child relationship, while other relationships may be more directly related to dating anxiety. Positive romantic outcomes have been related to the parental marital relationship quality and it is possible that further examination of the parental marital relationship could provide information about adolescent dating anxiety (Feldman, Gowen, \& Fisher, 1998; Simon \& Furman, 2010). Perhaps conflict in the parental marital relationship results in adolescents interpreting romantic relationships as conflict-ridden 
and therefore worthy of avoiding or directly anxiety provoking. Marital conflict also could be one of the means through which negative father-child interchanges are related to dating anxiety. For example, highconflict marriages are related to higher use of physical punishment and the occurrence of childhood socioemotional problems (Eamon, 2001). Further examination of the marital relationship and the mechanisms through which it is related to romantic outcomes for adolescents could illuminate developmental contributors to dating anxiety. The current composition of families in the United States complicates the way that this variable can be researched and presents many decisions for researchers. Examining the parental marital relationship would require defining the marital relationship in question (e.g. cohabitating parents or biological parents). A broader inclusion of the romantic relationship the adolescent has most access to could be more inclusive, but would not detect the effects the relationship between biological parents. There are many adolescents who have more than one set of parents and therefore have more than one model for how to engage in romantic relationships. Future research in this area should clearly define the samples they choose to research in order to properly address these potential differences.

Adolescent romantic development is an important part of adolescent social development and therefore should be considered in the social context. Many of the previous findings in regard to dating anxiety were related to peer variables including more other-sex friends and prior dating experiences. Adolescents report that adults provide the most accurate information about romantic relationships, but that peers provide the most information and have the greatest influence over partner selection (Wood, Senn, Desmarais, Park, \&Verberg, 2002). It is possible that peer dyadic variables may be more indicative of romantic development and dating anxiety through mechanisms such as fear-conditioning. Research including peer reports or peer dyadic behavior might also inform how an adolescent develops dating anxiety. It is possible that preexisting social anxiety is related to the development of dating anxiety, or peers might communicate threatening information about dating situations that inhibit adolescents who are more prone to avoid social situations. 


\section{Dating rules discussion task design.}

To our knowledge, this was the first study to examine parent-reported rationales and consequences for dating rules, or include a dating rules discussion task. While only a few of the codes were relevant to dating anxiety, the self-reported dating rules, rationales, consequences, and the discussion task may be useful in future examinations of adolescent romantic relationships and parental involvement. With the exception of the degree of control ratings, all of the written rule codes had good interrater reliability. Except for removal of privilege consequences and dating restriction consequences the remaining codes had good interrater reliability. These two codes had moderate agreement. Coders confused these two codes, indicating that either the coding rubric or coder trainings were insufficient to obtain good interrater agreement. Unfortunately, dating restriction consequences were one of the strongest predictors of dating anxiety and although agreement for this code was moderate, it has one of the lowest interrater reliability scores on the written rule task. Future research using these codes should spend considerable time and effort clarifying the distinction between dating restriction consequences and removal of privilege consequences. For the purpose of this study, dating restriction consequences were only coded if the father explicitly indicated that dating would be limited in the future. Even with these guidelines, some paternal verbalizations during the discussion task were ambiguous. For example, a father might have said, "If you break this rule, then you will not be allowed to go in the future." The rule would have been broken in the context of a date, and therefore dating could be the implied future context. To clarify the distinction for future coding, it might be useful to provide consequence options on the form for written rules, or to have researchers conduct queries after the task to clarify potentially ambiguous consequences. All of these codes could be useful for future use with the exception of the degree of control rating, which would need considerable improvement to the coding anchors. The current anchors are on a five-point scale ranging from no restriction to extremely prohibitive with very little clarification. Future anchors could be measured on a scale indicating how likely it would be for the adolescent to be able to date. The least restrictive rating (1) would indicate that the adolescent would not have any difficulty dating because the parents are not involved. The next rating (2) would indicate that the adolescent would 
be able to date with only minimal parental involvement. The moderate rating (3) would indicate that the adolescent would be able to date with a reasonable level of control. A more restrictive rating (4) would be given for adolescents who would be allowed to date, but parental rules would make dating difficult. The most restrictive rating (5), would indicate that the adolescent would be unable to date due to parental involvement.

The dating rules discussion task had greater variability is interrater reliability for coding rules, rationales, and consequences than the written rules task. Rule types had moderate to substantial agreement as did rule rationales with the exception of integrity rationales. Coding of integrity rationales was highly unreliable due to low base rates of the behavior in the discussion task. To correct this problem, integrity rationales could conceptually be combined with rationales indicating that a rule was in place to protect other interests. Interrater reliability for consequences were the most problematic codes for the discussion task, with verbal and unclear or no consequences having good agreement, removal of privileges having moderate agreement, dating restrictions having fair agreement, and natural consequences only having slight agreement. Coding consequences during the discussion task was not consistent and therefor less reliable than coding on the written task. Consistent with recommendations for written rule coding, coding rubrics for consequences should be clarified and coders trained more thoroughly in order to improve reliability. Contrary to other codes, the degree of control coding was more reliable for the dating rules discussion task than for the written rules. This improvement in reliability is likely due to the inclusion of fathers' tone of voice and nonverbal indicators available to coders during the discussion task.

While the reliability of many codes were less reliable for the discussion task, the task did provide data that was not available from written rules alone including dyadic variables. Interrater reliability scores for paternal flexibility and child questioning or challenging were good, while child engagement and discomfort scores were moderate. Paternal discomfort and checking-in scores were fair. While some of these reliability scores are lower than would be recommended, this is the first time these codes have been used and coding anchors could be clarified to improve their applicability for future use.

When considering the applicability of the discussion task, it is important to identify that no 
significant findings related to dating anxiety were related to discussion task scores. Given the lack of significant findings from the dating rules discussion and the more significant relations between written rule variables and dating anxiety, it is unclear whether the dating rules discussion was a useful means of examining paternal dating rules and dating anxiety. This task was included to assess for dyadic features of paternal rule use and included only fathers in order to improve scientific control by eliminating potential differences between mothers and fathers. The measures other than the dating rules discussion could have been administered on paper in approximately two thirds of the time, would not require a sterile testing environment, and could even be administered remotely via computer. If written dating rules, rationales, and consequences are more predictive of dating anxiety than the dating discussion task, future research in this area could be conducted more easily with lower costs and less demands on participants and researchers. Less invasive and restrictive means of data collection could also improve the generalizability of results by broadening the ability of adolescents and fathers to participate. If fathers and adolescents did not have to complete the study simultaneously, busier adolescents could have participated at their convenience independent of paternal availability. Mothers could also be included in the examination just as easily. More anxious adolescents many have been more willing to participate if they could participate at home via computer rather than having to complete surveys with a researcher present. More participants could also be included with ease in order to increase the power to detect relations between study variables.

The variability in length was problematic in developing codes for this task. Adolescent participation could have been coded based on the amount of time the adolescent spoke instead of interval ratings of engagement. There are a few ways that the task could be lengthened for future use. It is possible that the dating rules discussion task was too ambiguous for fathers. Many of the fathers expressed that they did not yet have a use for dating rules. Therefore, fathers who may have been more overprotective may have omitted rules they will enforce later in their adolescent's romantic development. Also, It is likely that more inhibited adolescents are already aware of their father's overprotective nature and are therefore less likely to need rules explicitly stating what they are not allowed to do. In order to 
elicit more indicators of overcontrol, the discussion task could be improved by adding hypothetical dating situations for fathers and adolescents to discuss. For example, Yeater and Viken (2010) used hypothetical dating situations to assess for risk-taking among women who had and had not experienced sexual victimization. These vignettes assessed for a women's willingness to refuse to be in certain situations that posed varying levels of risk. These vignettes could be modified to be developmentally appropriate for adolescent dating, and to assess for the parent's willingness to allow their child to be in these situations as opposed to assessing for the individual's willingness.

\section{Summary}

This study illuminated the importance of the father-child relationship and parental involvement in adolescent dating in the presentation of dating anxiety. Specifically, paternal use of dating restriction consequences for rule violations and adolescents reporting negative interchanges with fathers were related to higher levels of dating anxiety. This study utilized both a written and discussion based open-ended task to measure parental rule use, rule rationales and consequences for rule violations. This task was useful for examining rules, rationales, and consequences that parents use in regard to adolescent dating, and can be utilized and modified for future research. Future studies in the area of dating anxiety could illuminate more specific ways in which the father-child relationship is related to anxiety by examining more restricted samples of adolescents and expanding the ways that paternal involvement is measured. The addition of mothers and peers could also provide more information about the socialization of dating anxiety. Identifying variables that contribute to dating anxiety could lead to interventions that consequentially improve both adolescent romantic relationship development and the quality of adult romantic relationships. 


\section{References}

Anhalt, K., \& Morris, T. L. (2008). Parenting characteristics associated with anxiety and depression: A multivariate approach. Journal of Early Intensive Behavioural Intervention, 3, 122-137.

Barrett, P. M., Fox, T., \& Farrell, L. J. (2005). Parent-child interactions with anxious children and with their siblings: An observational study. Behaviour Change, 22, 220-236. doi:10.1375/bech.22.4.220

Bogels, S., \& Phares, V. (2007). Fathers' role in the etiology, prevention and treatment of child anxiety: A review and new model. Clinical Psychology Review, 28, 539-558. doi:10.1016/j.cpr.2007.07.011

Brown, B. (1999). 'You're going out with who?': Peer group influences on adolescent romantic relationships. In W. Furman, B. Brown, \& C. Feiring (Eds.), The development of romantic relationships in adolescence (pp. 291-329). New York: Cambridge University Press.

Bruggen, C., Stams, G.J., \& Bogels, S.M. (2008). The relation between child and parent anxiety and parental control: a meta-analytic review. Journal of Child Psychology and Psychiatry 49, 12571269. doi:10.1111/j.1469-7610.2008.01898.x

Collins, W. A, \& Sroufe, L. A. (1999). Capacity for intimate relationships: A developmental construction. In W. Furman, B. Brown, \& C. Feiring (Eds.), The development of romantic relationships in adolescence (pp. 125-147). New York: Cambridge University Press.

Connolly, J. A., \& Konarski, R. (1994). Peer self-concept in adolescence: Analysis of factor structure and of associations with peer experience. Journal of Research on Adolescence, 4, 385-403. doi: $10.1207 / \mathrm{s} 15327795 \mathrm{jra} 0403 \_3$

Deptula, D. P., Henry, D. B., \& Schoeny, M. E. (2010). How can parents make a difference? Longitudinal associations with adolescent sexual behavior. Journal of Family Psychology, 24, 731-739. doi:10.1037/a0021760

Eamon, M. K. (2001). Antecedents and socioemotional consequences of physical punishment on children in two-parent families. Child Abuse and Neglect, 25, 787-802.

Feldman, S. S., Gowen, L. K., \& Fisher, L. (1998). Family relationships and gender as predictors of 
romantic intimacy in young adults: a longitudinal study. Journal of Research on Adolescence, 8 , 263-286. doi: 10.1207/s15327795jra0802_5

Field, A. P., Ball, J. E., Kawycz, N. J., Moore, H. (2007). Parent-child relationships and the verbal information pathway to fear in children: two preliminary experiments. Behavioral and Cognitive Psychotherapy, 35, 473-486. doi: 10.1017/S1352465807003736

Field, A. P. \& Lawson, J. (2003) Fear information and the development of fears during childhood: Effects on implicit fear responses and behavioural avoidance. Behaviour Research and Therapy, 41, $1277-1293$.

Field, A. P., Lawson, J., \& Banerjee, R. (2008). The verbal threat information pathway to fear in children: the longitudinal effects of fear cognitions and the immediate effects on avoidance behavior. Journal of Abnormal Psychology, 117, 214-224. doi: 10.1037/0021-843X.117.1.214

Field, A. P., \& Storksen-Coulson, H. (2007). The interaction and pathways to fear in childhood anxiety: A preliminary study. Behaviour Research and Therapy, 45, 3051-3059. doi:

10.1016/j.brat.2007.09.001

Forbes, C., Vuchinich, S., \& Kneedler, B. (2001). Assessing families with the family problem solving code. In Kerig, P. K. \& Lindahl, K. M. (Eds.), Family observation coding systems. (pp. 59-75). Mahwah, New Jersey: Lawrence Erlbaum Associates.

Furman, W., \& Buhrmester, D. (1985). Children's perceptions of the personal relationships in their social networks. Developmental Psychology, 21, 1016-1024.

Furman, W., \& Buhrmester, D. (1992). Age and sex differences in perceptions of networks of personal relationships. Child Development, 63, 103-115.

Glickmann, A. R., \& La Greca, A. M. (2004). The Dating Anxiety Scale for Adolescents: Scale development and associations with adolescent functioning. Journal of Clinical Child and Adolescent Psychology, 33, 566-578. doi:10.1207/s15374424jccp3303_14

Gray, M. R., \& Steinberg, L. (1999). Adolescent romance and the parent-child relationship: A contextual perspective. In W. Furman, B. Brown, \& C. Feiring (Eds.), The development of romantic 
relationships in adolescence (pp. 235-262) New York: Cambridge University Press.

Greco, L. A., \& Morris, T. L. (2002). Paternal child-rearing style and child social anxiety: Investigation of child perceptions and actual father behavior. journal of Psychopathology and Behavioral Assessment, 24, 259-267. doi: 10.1023/A:1020779000183

Greco, L. A., \& Morris, T. L. (2005). Factors influencing the link between social anxiety and peer acceptance: Contributions of social skills and close friendships during middle childhood. Behavior Therapy, 36, 197-205. doi:10.1016/S0005-7894(05)80068-1

Hazan, C., \& Shaver, P. R. (1987). Romantic love conceptualized as an attachment process. Journal of Personality and Social Psychology, 52, 511-524.

Hazan, C., \& Shaver, P. R. (1994). Attachment as an organizational framework for research in close relationships. Psychological Inquiry, 5, 1-22. doi:10.1207/s15327965pli0501_1

Hudson, J. L. Rapee, R. M. (2005). Parental perceptions of overprotections: Specific to anxious children or shared between siblings? Behaviour Change, 22, 185-194. doi: 10.1375/bech.2005.22.3.185

Kan, M. L., McHale, S. M., \& Crouter, A. C. (2008). Parental involvement in adolescent romantic relationships: Patterns and correlates. Journal of Youth and Adolescence, 37, 168-179. doi: $10.1007 / \mathrm{s} 10964-007-9185-3$

La Greca, A. M., \& Mackey, E. R. (2007). Adolescents' anxiety in dating situations: The potential role of friends and romantic partners. Journal of Clinical Child and Adolescent Psychology, 36, 522-533. doi: $10.1080 / 15374410701662097$

Landis, J. R.; \& Koch, G. G. (1977). The measurement of observer agreement for categorical data. Biometrics 33, 159-174. doi:10.2307/2529310

Larson, J. H., Taggart-Reedy, M., \& Wilson, S. M. (2001). The effects of perceived dysfunctional familyof-origin rules on the dating relationships of young adults. Contemporary Family Therapy, 23, 489-512. doi: 10.1023/A:1013009213860

Lawson, J., Banerjee, R., \& Field, A. P. (2007). The effects of verbal information on children's fear 
beliefs about social situations. Behaviour Research and Therapy, 45, 21-37. doi:

10.1016/j.brat.2006.01.007

Madsen, S. D. (2008). Parents' management of adolescents' romantic relationships through dating rules: Gender variations and correlates of relationship qualities. Journal of Youth and Adolescence, 37, 1044-1058. doi:10.1007/s10964-008-9313-8

Madsen, S.D. \& Collins, W.A. (2011). The salience of adolescent romantic experiences for romantic relationship qualities in young adulthood. Journal of Research on Adolescence, 21, 789-801. doi: 10.1111/j.1532-775.2011.00737.x

Messer, S. C., \& Beidel, D. C. (1994). Psychosocial correlates of childhood anxiety disorders. Journal of American Academy of Child and Adolescent Psychiatry, 33, 975-983. doi:10.1097/00004583199409000-00007

Miller, B. C., McCoy, J. K., Olson, T. D., \& Wallace, C. M. (1986). Parental discipline and control attempts in relation to adolescent sexual attitude and behavior. Journal of Marriage and the Family, 48, 503-512. doi: 10.2307/352036

Mounts, N. S. (2001). Young adolescents' perceptions of parental management of peer relationships. The Journal of Early Adolescence, 21, 92-122. doi:10.1177/0272431601021001005

Mounts, N. S. (2004). Adolescents' perceptions of parental management of peer relationships in an ethnically diverse sample. Journal of Adolescent Research, 19, 446-467. doi: $10.1177 / 0743558403258854$

Padillia-Walker, L. M., \& Carlo, G. (2004). "It's not fair!" Adolescents' constructions of appropriateness of parental reactions. Journal of Youth and Adolescence, 35, 389-401. doi: 10.1023/B:JOYO.0000037632.46633.bd

Parkes, A., Henderson, M., Wight, D., \& Nixon, C. (2010). Is parenting associated with teenagers' early s sexual risk-taking, autonomy, and relationship with sexual partners? Perspectives on Sexual and Reproductive Health, 43, 30-40. Doi: 10.1363/4303011

Roisman, G. I., Madsen, S. D., Hennighausen, K. H., Sroufe, L. A., \& Collins, W. A. (2001). The 
coherence of dyadic behavior across parent-child and romantic relationships as mediated by the internalized representation of experience. Attachment and Human Development, 3, 156-172. doi: $10.1080 / 14616730110056946$

Rork, K. E., \& Morris, T. L. (2009). Influence of parenting factors on childhood social anxiety: Direct observation of parental warmth and control. Child and Family Behavior Therapy, 31, 220235. doi:10.1080/07317100903099274

Seiffge-Krenke, I., Shulman, S., \& Klessinger, N. (2001). Adolescent precursors of romantic relationships in young adulthood. Journal of Social and Personal Relationships, 18, 327-346. doi:

\section{$10.1177 / 026540750118300$}

Seiffge-Krenke, I. (2003). Testing theories of romantic development from adolescence to adulthood: evidence of a developmental sequence. International Journal of Behavioral Development, 27, 519-531. doi: 10.1080/01650250344000145

Siqueland, L., Kendall, P. C., \& Steinberg, L. (1996). Anxiety in children: Perceived family environments and observed family interaction. Journal of Clinical Child Psychology, 25, 225-237. doi: $10.1207 / \mathrm{s} 15374424 \mathrm{jccp} 2502 \_12$

Silverman, W. K., Cerny, J. A., Nelles, W. B., \& Burke, A. E. (1988). Behavior problems in children of parents with anxiety disorders. Journal of the American Academy of Child \& Adolescent Psychiatry, 27, 779-784.

Simon, V.A. \& Furman, W. (2010). Interparental conflict and adolescents romantic relationship conflict. Journal of Research on Adolescene, 20. 188 - 209. doi: 10.111/j.1532-7795.2009.00635.x

Smetana, J. G., \& Asquith, P. (1994). Adolescents' and parents' conceptions of parental authority and personal autonomy. Child Development, 65, 1147-1162. doi: 10.2307/1131311

Smetana, J. G., \& Gettman, D. C. (2006). Autonomy and relatedness with parents and romantic development in African American adolescents. Developmental Psychology, 42, 1347-1351. doi:10.1037/0012-1649.42.6.1347

Sumter, S. R., Bokhorst, C. L., \& Westenberg, P.M. (2009). Social fears during adolescence: Is there an 
increase in distress and avoidance? Journal of Anxiety Disorders, 23, 897 - 903.

Tanner, J. F., Carlson, L. A., Raymond, M. A., \& Hopkins, C. D. (2008). Reaching parents to prevent adolescent risky behavior: Examining the effects of threat portrayal and parenting orientation on parental participation perceptions. Journal of Public Policy and Marketing, 27, 149-155. doi: 10.1509/jppm.27.2.14

Wood, E., Senn, C. Y., Desmarais, S., Park, L., \& Verberg, N. (2002). Sources of information about dating and their perceived influence on adolescents. Journal of Adolescent Research, 17, 401-417.

Yeater, E. A., \& Viken, R. J. (2010). Factors affecting women's response choices in dating and social situations. Journal of Interpersonal Violence, 25, 1411 - 1428. 
Table 1

Continuous Demographic Variables by Gender

\begin{tabular}{lcccccc}
\hline \multicolumn{7}{c}{ Adolescent Gender } \\
\hline Demographic Variable & \multicolumn{2}{c}{ Male } & \multicolumn{2}{c}{ Female } & \multicolumn{2}{c}{ Total } \\
\hline & $M$ & $S D$ & $M$ & $S D$ & $M$ & $S D$ \\
Adolescent Age & 15.30 & 1.21 & 15.20 & 1.10 & 15.25 & 1.14 \\
Paternal Age & & & & & & \\
& 50.17 & 8.60 & 49.37 & 8.91 & 49.77 & 8.69 \\
& & & & & & \\
\hline
\end{tabular}


Table 2

Categorical Demographic Variables by Gender

Adolescent Gender

\begin{tabular}{|c|c|c|c|}
\hline Demographic Variable & Male $(n=30)$ & Female $(n=30)$ & Total $(N=60)$ \\
\hline \multicolumn{4}{|l|}{ Adolescent Race } \\
\hline White & $23(77 \%)$ & $26(87 \%)$ & $49(82 \%)$ \\
\hline Black & $6(20 \%)$ & $2(7 \%)$ & $8(13 \%)$ \\
\hline Native American & $0(0 \%)$ & $2(7 \%)$ & $3(5 \%)$ \\
\hline Other & $1(3 \%)$ & $0(0 \%)$ & $1(2 \%)$ \\
\hline \multicolumn{4}{|l|}{ Adolescent Grade } \\
\hline Freshmen & $9(30 \%)$ & $10(67 \%)$ & $19(32 \%)$ \\
\hline Sophomore & $13(43 \%)$ & $11(27 \%)$ & $24(40 \%)$ \\
\hline Junior & $3(10 \%)$ & $6(20 \%)$ & $9(15 \%)$ \\
\hline Senior & $5(17 \%)$ & $3(10 \%)$ & $8(13 \%)$ \\
\hline \multicolumn{4}{|l|}{ Dating Status } \\
\hline Non-dater & $5(17 \%)$ & $6(20 \%)$ & $11(18 \%)$ \\
\hline Inactive Dater & $14(47 \%)$ & $8(27 \%)$ & $22(37 \%)$ \\
\hline Active Dater & $11(37 \%)$ & $16(53 \%)$ & $27(45 \%)$ \\
\hline \multicolumn{4}{|l|}{ Paternal Relationship } \\
\hline Biological Father & $23(77 \%)$ & $24(80 \%)$ & $47(78 \%)$ \\
\hline Stepfather & $3(10 \%)$ & $3(10 \%)$ & $6(10 \%)$ \\
\hline Biological Grandfather & $1(3 \%)$ & $2(7 \%)$ & $3(5 \%)$ \\
\hline Adoptive Father & $1(3 \%)$ & $1(3 \%)$ & $2(3 \%)$ \\
\hline Mother's fiancé & $1(3 \%)$ & $0(0 \%)$ & $1(2 \%)$ \\
\hline Maternal Uncle & $1(3 \%)$ & $0(0 \%)$ & $1(2 \%)$ \\
\hline
\end{tabular}


Dating Anxiety 50

\section{Adolescent Gender}

\begin{tabular}{llll}
\hline Demographic Variable & Male $(n=30)$ & Female $(n=30)$ & Total $(N=60)$ \\
\hline Father's Race & $24(80 \%)$ & $25(83 \%)$ & $49(82 \%)$ \\
White & $5(17 \%)$ & $2(7 \%)$ & $7(23 \%)$ \\
Black & $0(0 \%)$ & $3(10 \%)$ & $3(5 \%)$ \\
Native American & $1(3 \%)$ & $0(0 \%)$ & $1(2 \%)$ \\
Other & & \\
\hline
\end{tabular}


Table 3

Intercoder Reliability for Written Rules and Dating Rules Discussion Task

\begin{tabular}{|c|c|c|c|}
\hline Variable & $k w$ & $\mathrm{SE}$ & $95 \% \mathrm{CI}$ \\
\hline \multicolumn{4}{|l|}{ Written Rules Task } \\
\hline Degree of Control & .21 & .19 & $-.16-.58$ \\
\hline Supervision Rules & .88 & .10 & $.68-1.00$ \\
\hline Restriction Rules & .78 & .17 & $.49-1.00$ \\
\hline Prescription Rules & .83 & .08 & $.66-.99$ \\
\hline Sex Rationale & .75 & .23 & $.30-1.00$ \\
\hline Healthy Relationships Rationale & .83 & .18 & $.48-1.00$ \\
\hline Safety Rationale & 1.00 & .00 & $1.00-1.00$ \\
\hline Interests Rationale & 1.00 & .00 & $1.00-1.00$ \\
\hline Control Rationale & 1.00 & .00 & $1.00-1.00$ \\
\hline Integrity Rationale & 1.00 & .00 & $1.00-1.00$ \\
\hline Unclear Rationale/ No Rationale & 1.00 & .00 & $1.00-1.00$ \\
\hline Verbal Consequence & 1.00 & .00 & $1.00-1.00$ \\
\hline Dating Restriction Consequence & .51 & .22 & $.09-.94$ \\
\hline Removal of Privileges Consequence & .60 & .20 & $.21-.98$ \\
\hline Natural Consequences & 1.00 & .00 & $1.00-1.00$ \\
\hline No Consequences/Unclear & .84 & .12 & $.61-1.00$ \\
\hline \multicolumn{4}{|l|}{ Dating Rules Discussion } \\
\hline Degree of Control & .43 & .14 & $.15-.71$ \\
\hline Supervision Rules & .89 & .08 & $.74-1.00$ \\
\hline Restriction Rules & .62 & .15 & $.34-.90$ \\
\hline Prescription Rules & .72 & .14 & $.45-1.00$ \\
\hline Sex Rationale & 1.00 & .00 & $1.00-1.00$ \\
\hline
\end{tabular}




\begin{tabular}{|c|c|c|c|}
\hline Variable & $k w$ & $\mathrm{SE}$ & $95 \% \mathrm{CI}$ \\
\hline Healthy Relationships Rationale & .84 & .07 & $.71-.97$ \\
\hline Safety Rationale & .70 & .08 & $.54-.86$ \\
\hline Interests Rationale & .67 & .16 & $.35-.99$ \\
\hline Control Rationale & .69 & .12 & $.45-.92$ \\
\hline Integrity Rationale & .00 & .00 & $.00-.00$ \\
\hline Unclear Rationale/ No Rationale & .90 & .10 & $.70-1.00$ \\
\hline Verbal Consequence & .65 & .02 & $.61-.69$ \\
\hline Dating Restriction Consequence & .25 & .32 & $-.37-.87$ \\
\hline Removal of Privileges Consequence & .47 & .21 & $.06-.88$ \\
\hline Natural Consequences & .09 & .24 & $-.37-.56$ \\
\hline No Consequences/Unclear & .66 & .12 & $.42-.89$ \\
\hline Child Discomfort & .50 & .15 & $.21-.78$ \\
\hline Child Questioning/Challenging & .93 & .07 & $.80-1.00$ \\
\hline Child Engagement & .48 & .12 & $.26-.71$ \\
\hline Paternal Discomfort & .38 & .20 & $-.01-.77$ \\
\hline Paternal Checking-in & .28 & .22 & $-.16-.72$ \\
\hline Paternal Flexibility & 1.00 & .00 & $1.00-1.00$ \\
\hline
\end{tabular}


Table 4

Gender Differences on Paternal Variables

\begin{tabular}{lllllll}
\hline & \multicolumn{7}{c}{ Adolescent Gender } & & & \\
\hline Parenting Variable & Male & & Female & & $F(1,58)$ & $p$ \\
\hline Supervision Rules - Written & 0.48 & 0.78 & 1.53 & 1.36 & $16.28^{* * *}$ & .001 \\
Control Rationales - Written & 1.00 & 1.02 & 1.77 & 1.61 & $4.85^{*}$ & .050 \\
Control Rationales - Discussion & 0.97 & 0.87 & 1.60 & 1.33 & $4.69^{*}$ & .050 \\
PIARR-R Autonomy & 8.50 & 1.59 & 7.53 & 2.08 & $4.09^{*}$ & .048 \\
Sex Rationales - Discussion & 0.69 & 0.81 & 0.30 & 0.47 & $5.21^{*}$ & .050 \\
\hline
\end{tabular}

Note. Discussion tasks are have $F(1,57)$ degrees of freedom due to one missing participant data. $* p<.05$.

$* * p<.01 . * * * p<.001$ 
Table 5

Dating Status Differences based on Age, DAS-A Scores, SPAI Scores

\begin{tabular}{lcccccccc}
\hline \multicolumn{1}{c}{ Dating Status } \\
\hline Parenting Variable & \multicolumn{1}{c}{ Active Daters } & \multicolumn{1}{l}{ Inactive Daters } & \multicolumn{1}{c}{ Non-Daters } & $F(2,57)$ & $p$ \\
\hline & $M$ & $S D$ & $M$ & $S D$ & $M$ & $S D$ & & \\
Age & 15.26 & 0.98 & 15.68 & 1.25 & 14.36 & 0.81 & $5.63^{* *}$ & .006 \\
DAS-A Total & 50.67 & 18.29 & 53.59 & 17.72 & 56.78 & 20.85 & 0.408 & .667 \\
DAS-A FNE & 26.26 & 9.59 & 27.86 & 9.73 & 28.44 & 11.60 & 0.240 & .788 \\
DAS-A SAD - & 17.15 & 6.94 & 18.09 & 6.05 & 20.11 & 6.33 & 0.703 & .500 \\
Dating & 7.26 & 3.27 & 7.63 & 3.29 & 8.00 & 4.24 & 0.186 & .830 \\
DAS-A SAD - Group & 76.00 & 39.19 & 64.30 & 32.18 & 61.13 & 31.77 & 0.99 & .378 \\
SPAI & & & & & & & \\
\hline
\end{tabular}

Note. DAS-A is the Dating Anxiety Scale for Adolescents. FNE is Fear of Negative Evaluation. SAD Dating is Social Distress -Dating. SAD - Group is Social Distress - Groups. SPAI is the Social Phobia and Anxiety Scale. ${ }^{* *} p<.01$ 
Table 6

Paternal Predictors of DAS-A Total Scores

\begin{tabular}{lcc}
\hline \multirow{2}{*}{ Variable } & \multicolumn{2}{c}{ DAS-A Total Scores } \\
\cline { 2 - 3 } & \multicolumn{1}{c}{$B$} & $p$ \\
\hline Constant & $60.05^{* * *}$ & .000 \\
Restriction Rules - Discussion & 0.001 & .995 \\
Safety Rationales - Discussion & 0.221 & .103 \\
PIARR-R Concern & -0.106 & .457 \\
\hline$R^{2}$ & .06 & \\
$F$ & 1.15 & \\
\hline$* * * p<.001$ & &
\end{tabular}


Table 7

Correlations Among Paternal Parenting Variables Associated with Dating Anxiety

\begin{tabular}{|c|c|c|c|c|c|c|c|c|c|c|c|c|c|c|c|c|}
\hline Measures & 1 & 2 & 3 & 4 & 5 & 6 & 7 & 8 & 9 & 10 & 11 & 12 & 13 & 14 & 15 & 16 \\
\hline 1. DAS-A & - & -.11 & .00 & .17 & $.28 *$ & .21 & $.36 * *$ & .04 & -.02 & .22 & .07 & .19 & -.03 & .12 & -.04 & .19 \\
\hline 2. PIAR-R-Concern & -.11 & - & $.52 * *$ & $.28 *$ & .04 & .17 & $.31 *$ & .03 & $.33 *$ & -.05 & $.33 * *$ & .17 & -.12 & .20 & .16 & -.04 \\
\hline $\begin{array}{l}\text { 3. PIAR-R- } \\
\text { Restriction }\end{array}$ & .00 & $.52 * *$ & - & .08 & -.13 & .04 & .14 & -.18 & .02 & -.16 & .04 & .03 & $-.33 *$ & .17 & -.20 & .01 \\
\hline $\begin{array}{l}\text { 4. Restriction Rules- } \\
\text { Written }\end{array}$ & .17 & $.28 *$ & .08 & - & .21 & $.27 *$ & $.33^{*}$ & $.29 *$ & $.84 * *$ & .12 & $.44 * *$ & .21 & .12 & $.38 * *$ & -.02 & .26 \\
\hline $\begin{array}{l}\text { 5. Safety Rationales } \\
\text {-Written }\end{array}$ & $.28 *$ & .04 & -.13 & .21 & - & $.51 * *$ & $.49 * *$ & $.49 * *$ & .11 & $.82 * *$ & $.44 * *$ & .11 & .23 & .23 & -.11 & $.36^{* *}$ \\
\hline $\begin{array}{l}\text { 6. Control } \\
\text { Rationales- } \\
\text { Written }\end{array}$ & .21 & .17 & .04 & $.27^{*}$ & $.51 * *$ & - & $.46^{* *}$ & $.38 * *$ & $.26^{*}$ & $.41 * *$ & $.69 * *$ & $.39 * *$ & -.21 & .20 & -.10 & .22 \\
\hline $\begin{array}{l}\text { 7. Dating Restriction } \\
\text {-Written }\end{array}$ & $.36^{* *}$ & $.31 *$ & .14 & $.33^{*}$ & $.49 * *$ & $.46^{* *}$ & - & -.22 & $.41 * *$ & .22 & $.44 * *$ & $.74 * *$ & -.15 & .00 & .07 & .11 \\
\hline $\begin{array}{l}\text { 8. Removal of } \\
\text { Privileges - } \\
\text { Written }\end{array}$ & .04 & .03 & -.18 & $.29 *$ & $.49 * *$ & $.38 * *$ & -.22 & - & $.26^{*}$ & $.44 * *$ & $.33^{*}$ & -.12 & $.63 * *$ & .25 & .25 & $.39 * *$ \\
\hline $\begin{array}{l}\text { 9. Restriction Rules- } \\
\text { Discussion }\end{array}$ & -.02 & $.33^{*}$ & .02 & $.84 * *$ & .11 & $.26 *$ & $.41 * *$ & $.26^{*}$ & - & .07 & $.47 * *$ & $.39 * *$ & .19 & .20 & -.09 & .12 \\
\hline
\end{tabular}




\begin{tabular}{|c|c|c|c|c|c|c|c|c|c|c|c|c|c|c|c|c|}
\hline $\begin{array}{l}\text { 10. Safety } \\
\text { Rationales - } \\
\text { Discussion }\end{array}$ & .22 & -.05 & -.16 & .12 & $.82 * *$ & $.41 * *$ & .22 & $.44^{* *}$ & .07 & - & $.37 * *$ & .16 & $.30 *$ & .24 & -.20 & $.41 * *$ \\
\hline $\begin{array}{l}\text { 11. Control } \\
\text { Rationales- } \\
\text { Discussion }\end{array}$ & .07 & $.33 * *$ & .04 & $.44 * *$ & $.44 * *$ & $.69 * *$ & $.44 * *$ & $.33^{*}$ & $.47 * *$ & $.37 * *$ & - & $.40 * *$ & .17 & $.36^{* *}$ & .02 & .14 \\
\hline $\begin{array}{l}\text { 12. Dating } \\
\text { Restriction - } \\
\text { Discussion }\end{array}$ & .19 & .17 & .03 & .21 & .11 & $.39 * *$ & $.74 * *$ & -.12 & $.39 * *$ & .16 & $.40 * *$ & - & .02 & -.12 & -.03 & .06 \\
\hline $\begin{array}{l}\text { 13. Removal of } \\
\text { Privileges - } \\
\text { Discussion }\end{array}$ & -.03 & -.12 & $-.33^{*}$ & .12 & .23 & -.21 & -.15 & $.63^{* *}$ & .19 & $.30^{*}$ & .17 & .02 & - & .02 & -.11 & .20 \\
\hline $\begin{array}{l}\text { 14. Paternal } \\
\text { Discomfort }\end{array}$ & .12 & .20 & .17 & $.38 * *$ & .23 & .20 & .00 & .25 & .20 & .24 & $.36^{* *}$ & -.12 & .02 & - & -.06 & .22 \\
\hline $\begin{array}{l}\text { 15. Paternal } \\
\text { Checking-in }\end{array}$ & -.04 & .16 & -.20 & -.02 & -.11 & -.10 & .07 & .25 & -.09 & -.20 & .02 & -.03 & -.11 & -.06 & - & .06 \\
\hline $\begin{array}{l}\text { 16. Paternal } \\
\text { Flexibility }\end{array}$ & .19 & -.04 & .01 & .26 & $.36^{* *}$ & .22 & .11 & $.39 * *$ & .12 & $.41 * *$ & .14 & .06 & .20 & .22 & .06 & - \\
\hline $\begin{array}{l}\text { 17. NRI - Neg. } \\
\text { Interchanges - } \\
\text { Father }\end{array}$ & $.30 *$ & -.02 & -.05 & .14 & .01 & -.16 & .06 & -.01 & .14 & .08 & -.19 & .02 & -.01 & -.03 & -.06 & .02 \\
\hline
\end{tabular}
Note. ${ }^{*} p<.05 .{ }^{* *} p<.01$. 
Table 8

Posthoc Paternal Predictors of DAS-A Total Scores

\begin{tabular}{lcc}
\hline & & DAS-A Total Scores \\
\cline { 2 - 3 } Variable & $B$ & $p$ \\
\hline Constant & $30.69^{* * *}$ & .000 \\
Dating Restriction - Written & $0.290^{*}$ & .025 \\
Safety Rationales - Written & 0.198 & .122 \\
NRI Negative Interchanges - Father & $0.273^{*}$ & .026 \\
\hline$R^{2}$ & .246 & .002 \\
$F$
\end{tabular}

${ }^{*} p<.05 .{ }^{* *} p<.01 .{ }^{* * *} p<.001$ 
Table 9

Gender Interactions for Paternal Predictors of DAS-A Total Scores

\begin{tabular}{lcc}
\hline & \multicolumn{2}{c}{ DAS-A Total Scores } \\
\cline { 2 - 3 } Variable & $B$ & $p$ \\
\hline Constant & $32.96^{* * *}$ & .000 \\
Dating Restriction - Written & $0.519^{* *}$ & .003 \\
Negative Interchanges - Father & 0.230 & .180 \\
Dating Restriction X Gender & -0.273 & .118 \\
Negative Interchanges X Gender & .114 & .558 \\
\hline$R^{2}$ & .248 & .004 \\
$F$ & $4.30 * *$ & \\
\hline$* p<.05 .{ }^{* *} p<.01 .{ }^{* * *} p<.001$ & &
\end{tabular}


Appendix A

\section{Wating Questionnaire \\ Dating Questionnair}

a. One-on-one outing (dinner, movie, etc.)

b. One-on-one staying in (rent video, "hang out")

c. Group outing with significant other and family

d. Group outing with significant other and friends

e. Group outing with significant other and acquaintances

\section{Have you ever been on a date or had a boy/girlfriend? (Circle One) Yes}

\section{If yes answer questions a through $\mathrm{g}$ below.}

a. Have you been on a date in the last 6 months?

Yes

No N/A

b. Have you had a boy/girlfriend in the last 6 months?

Yes

No

N/A

c. How old were you when you first went on a date or had a boy/girlfriend?

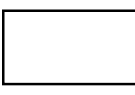

d. How many dating partners have you had in your lifetime?

(This can include boy/girlfriends and people you have dated more casually)

e. How long was your longest dating relationship?

(Can be measured in years, months, weeks, or days)

f. What kinds of dates have you been on? (Circle all that apply)

i. One-on-one outing (dinner, movie, etc.)

ii. One-on-one staying in (rent video, "hang out")

iii. Group outing with significant other and family

iv. Group outing with significant other and friends

v. Group outing with significant other and acquaintances

g. What kind of date have you been on most often? (Circle one)

i. One-on-one outing (dinner, movie, etc.)

ii. One-on-one staying in (rent video, "hang out")

iii. Group outing with significant other and family

iv. Group outing with significant other and friends

v. Group outing with significant other and acquaintances 
3. Do you currently have a boy/girlfriend? (Circle One)

If yes...

a. Are you (A) in a committed relationship or (B) casually dating? (Circle One)

b. How long have you been dating your significant other?

(Can be measured in years, months, weeks, or days)

4. Have you ever kissed a dating partner or anyone in a romantic or sexual way? Yes

No

If yes...

a. How old were you when you first kissed someone in this way?

5. Have you ever been sexually active?

Yes

No

(This can include behaviors such as oral sex)

If yes...

a. How old were you when you first engaged in sexual activity?

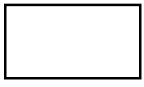

b. How many sexual partners have you had?

Yes

No

c. Have you ever had unprotected sex? 


\section{Appendix B}

\section{Parental Involvement in Adolescent Romantic Relationship}

For the following items please indicate how true the statement is for you and your child's dating behaviors. If your child is not currently in a dating relationship, please indicate how you have responded in your child's past dating relationships or how you would respond if they were dating.

\begin{tabular}{|c|c|c|c|c|}
\hline & $\begin{array}{l}\text { Strongly } \\
\text { Disagree }\end{array}$ & Disagree & Agree & $\begin{array}{l}\text { Strongly } \\
\text { Disagree }\end{array}$ \\
\hline \multicolumn{5}{|l|}{ I am concerned that... } \\
\hline ...having a girl/boyfriend takes time away from family. & 1 & 2 & 3 & 4 \\
\hline $\begin{array}{l}\text {...having a girl/boyfriend takes time away from my } \\
\text { child's friends. }\end{array}$ & 1 & 2 & 3 & 4 \\
\hline $\begin{array}{l}\text {...having a girl/boyfriend takes time away from other } \\
\text { important activities (e.g., sports, church). }\end{array}$ & 1 & 2 & 3 & 4 \\
\hline $\begin{array}{l}\text {..having a girl/boyfriend affects my child's school } \\
\text { work. }\end{array}$ & 1 & 2 & 3 & 4 \\
\hline ...my child will get too serious about the relationship. & 1 & 2 & 3 & 4 \\
\hline ...I won't like my child's girl/boyfriend. & 1 & 2 & 3 & 4 \\
\hline ...my child's girl/boyfriend might be too old for him $/$ her. & 1 & 2 & 3 & 4 \\
\hline ...having a girl/boyfriend costs too much money. & 1 & 2 & 3 & 4 \\
\hline $\begin{array}{l}\text {...my child might get involved with the wrong type of } \\
\text { kids because he/she has a girl/boyfriend. }\end{array}$ & 1 & 2 & 3 & 4 \\
\hline I am worried about my child holding hands or kissing. & 1 & 2 & 3 & 4 \\
\hline I am worried about my child making out. & 1 & 2 & 3 & 4 \\
\hline I am worried about my child engaging in sexual activity. & 1 & 2 & 3 & 4 \\
\hline $\begin{array}{l}\text { I worry that my child is just too young to have a } \\
\text { girl/boyfriend. }\end{array}$ & 1 & 2 & 3 & 4 \\
\hline $\begin{array}{l}\text { I encourage my child to invite his/her girl/boyfriend over } \\
\text { to our house. }\end{array}$ & 1 & 2 & 3 & 4 \\
\hline $\begin{array}{l}\text { I encourage my child to include his/her girl/boyfriend in } \\
\text { family activities. }\end{array}$ & 1 & 2 & 3 & 4 \\
\hline I talk with my child's girl/boyfriend. & 1 & 2 & 3 & 4 \\
\hline I try to meet my child's girl/boyfriend. & 1 & 2 & 3 & 4 \\
\hline $\begin{array}{l}\text { I spend time talking with my child about his/her } \\
\text { girl/boyfriend. }\end{array}$ & 1 & 2 & 3 & 4 \\
\hline I try to meet the parents of my child's girl/boyfriend. & 1 & 2 & 3 & 4 \\
\hline I spend time with my child and his/her girl/boyfriend. & 1 & 2 & 3 & 4 \\
\hline $\begin{array}{l}\text { I include my child's girl/boyfriend in family celebrations } \\
\text { and special occasions. }\end{array}$ & 1 & 2 & 3 & 4 \\
\hline $\begin{array}{l}\text { I tell my child if I don't like whom he/she has chosen for } \\
\text { a girl/boyfriend. }\end{array}$ & 1 & 2 & 3 & 4 \\
\hline
\end{tabular}




\begin{tabular}{|c|c|c|c|c|}
\hline $\begin{array}{l}\text { I arrange family activities so my child can't spend time } \\
\text { with his/her girl/boyfriend. }\end{array}$ & 1 & 2 & 3 & 4 \\
\hline $\begin{array}{l}\text { I keep my child busy at home (e. g., doing chores, } \\
\text { running errands, helping out) so he/she can't spend as } \\
\text { much time with his/her girl/boyfriend. }\end{array}$ & 1 & 2 & 3 & 4 \\
\hline $\begin{array}{l}\text { I encourage my child to spend time with family members } \\
\text { rather than with his/her girl/boyfriend. }\end{array}$ & 1 & 2 & 3 & 4 \\
\hline $\begin{array}{l}\text { I limit the amount of time my child spends with his/her } \\
\text { girl/boyfriend. }\end{array}$ & 1 & 2 & 3 & 4 \\
\hline $\begin{array}{l}\text { I limit how much time my child spends talking to his/her } \\
\text { girl/boyfriend on the phone. }\end{array}$ & 1 & 2 & 3 & 4 \\
\hline $\begin{array}{l}\text { I tell my child that whom he/she has as a girl/boyfriend is } \\
\text { his/her personal choice. }\end{array}$ & 1 & 2 & 3 & 4 \\
\hline $\begin{array}{l}\text { I tell my child to make his/her own decisions about } \\
\text { whom he/she chooses as a girl/boyfriend. }\end{array}$ & 1 & 2 & 3 & 4 \\
\hline $\begin{array}{l}\text { I tell my child that who he/she has as a girl/boyfriend is } \\
\text { his/her own business. }\end{array}$ & 1 & 2 & 3 & 4 \\
\hline I am concerned that my child may be homosexual. & 1 & 2 & 3 & 4 \\
\hline $\begin{array}{l}\text { I would be alright with my child telling me that they were } \\
\text { homosexual. }\end{array}$ & 1 & 2 & 3 & 4 \\
\hline
\end{tabular}


Appendix C

\section{Dating Rules}

Please take a moment to recall any rules you have in regard to your child dating. In the space below please write all of your dating rules, the reason you have this rule, and the consequences if your child breaks the rule.

Rule

Rationale

\section{Consequence}

Rule

Rationale

Consequence

Rule

Rationale

Consequence

Rule

Rationale

\section{Consequence}

Rule

Rationale

Consequence 
Rule

Rationale

Consequence

Rule

Rationale

\section{Consequence}

Rule

Rationale

Consequence

Rule

Rationale

Consequence

Rule

Rationale

\section{Consequence}

Rule

Rationale

Consequence 


\section{Appendix D}

\section{Dating Rules Coding Rubric}

\section{Dating Rules}

Fathers were asked to list dating rules, their rationale for the rule, and the consequence if the rule was broken.

Dating rules were transcribed for coding Each parent's rule set was rated on a 5-point scale developed by Madsen (2008) and the degree of control the set of rules offered regarding adolescents' dating activities. High ratings were given to parents who had extensive and explicit rules about the adolescent's dating behavior; taken as a whole, such rules were judged to heavily constrain the adolescent's dating activities (e.g., rules prohibiting dating, early curfews, rules limiting acceptable dating partners). Low ratings were given to parents who listed few rules or rules that would not interfere with the adolescent's dating activities (e.g., rules to simply keep the parent informed, rules to wear seatbelts). The lowest rating was given to parents reporting no dating rules. Each individual rule was categorized as providing supervision, restriction, or prescription. Rules that would provide the parent with information but would not preemptively restrict dating activities were coded as supervision rules (e.g., rules to inform the parents of plans). Rules that would constrain or limit the adolescent's dating activities were coded as restriction rules (e.g., curfews, rules prohibiting dating older partners). Rules that specified how the adolescent should behave on a date were coded as prescription rules (e.g., rules to open doors for a date, rules to treat a date with respect). Each rule was assigned to a single category.

Rationales- Each listed rationale can have one or more of the functions listed below. Each function stated in the rationale should be counted separately and a total of each rationale type determine for each participant.

\section{Consequence}

The consequence for breaking each rule should be coded as either a verbal reprimand, future dating restriction, punishment or removal of privileges, natural consequences, or no consequence.

\section{Degree of control}

1 - No restriction

2 - Somewhat permissive

3 - Moderate control

4 - Prohibitive

5 - Extremely prohibitive 


\begin{tabular}{|l|l|l|}
\hline Rule Type & Definition & Examples \\
\hline $\begin{array}{l}\text { Supervision } \\
\text { "Keep me } \\
\text { informed" }\end{array}$ & $\begin{array}{l}\text { Rules that require the adolescent to } \\
\text { provide information regarding his or } \\
\text { her dating activities }\end{array}$ & $\begin{array}{l}\text { Parents must meet the date } \\
\text { Check in once (call) during the evening } \\
\text { Parents must know where you are going } \\
\text { If plans change, we need to know } \\
\text { If they are going to a party, an address and phone } \\
\text { number are needed }\end{array}$ \\
\hline $\begin{array}{l}\text { Restriction } \\
\text { "Don't do } \\
\text { this" }\end{array}$ & $\begin{array}{l}\text { Rules that place some limitation or } \\
\text { constraint on the adolescent's dating } \\
\text { activity }\end{array}$ & $\begin{array}{l}\text { No dates on school nights } \\
\text { No, no, no sex! } \\
\text { No single dates - two or more couples } \\
\text { Curfew of 1:00 a.m. T } \\
\text { old places he can't go }\end{array}$ \\
\hline $\begin{array}{l}\text { Prescription } \\
\text { "Behave } \\
\text { this way" }\end{array}$ & $\begin{array}{l}\text { Rules that specify expectations } \\
\text { regarding how the adolescent should } \\
\text { behave with a date or in a dating } \\
\text { relationship }\end{array}$ & $\begin{array}{l}\text { Use good judgment } \\
\text { Be a gentleman/lady } \\
\text { Leave when a situation is making you } \\
\text { uncomfortable } \\
\text { Don't let someone domineer or walk over you } \\
\text { Before becoming sexually active both partners } \\
\text { need to discuss the issue } \\
\text { Prioritizing other activities }\end{array}$ \\
\hline
\end{tabular}

\begin{tabular}{|l|l|l|}
\hline Rationale type & Definition & Examples \\
\hline $\begin{array}{l}\text { Preventing or } \\
\text { controlling sexual } \\
\text { behaviors }\end{array}$ & $\begin{array}{l}\text { Rationales indicating that the adolescent } \\
\text { should not be engaging in sexual activities } \\
\text { including unprotected sex; including } \\
\text { implied }\end{array}$ & $\begin{array}{l}\text { STD's } \\
\text { Pregnancy } \\
\text { Unprepared for sex } \\
\text { Not "going too far" }\end{array}$ \\
\hline $\begin{array}{l}\text { Promoting a } \\
\text { Healthy Romantic } \\
\text { Relationship }\end{array}$ & $\begin{array}{l}\text { Rationales indicating that the rule either } \\
\text { limits unhealthy relationships or promotes } \\
\text { healthy relationships through mate } \\
\text { selection or relationship advice (excludes } \\
\text { monitoring partners) }\end{array}$ & $\begin{array}{l}\text { Promote shared interests } \\
\text { Improving partner selection } \\
\text { Giving relationship advice }\end{array}$ \\
\hline Safety & $\begin{array}{l}\text { Any rationale indicating that the rule is in } \\
\text { place to promote physical safety }\end{array}$ & $\begin{array}{l}\text { Driver safety } \\
\text { Safety }\end{array}$ \\
\hline $\begin{array}{l}\text { Protecting other } \\
\text { interests }\end{array}$ & $\begin{array}{l}\text { These rationales indicate that the rule is } \\
\text { used to protect other interests including } \\
\text { academics, friendships, or family ties }\end{array}$ & $\begin{array}{l}\text { School is too important } \\
\text { Family time }\end{array}$ \\
\hline $\begin{array}{l}\text { Environmental } \\
\text { control/monitoring }\end{array}$ & $\begin{array}{l}\text { The rationale simply implies a need for } \\
\text { control or monitioring without indicating } \\
\text { another function }\end{array}$ & $\begin{array}{l}\text { Keeping tabs } \\
\text { Knowing parents/significant other } \\
\text { Child unable to make decisions }\end{array}$ \\
\hline $\begin{array}{l}\text { Reputation or } \\
\text { personal integrity }\end{array}$ & $\begin{array}{l}\text { The rationale indicates that the rule serves } \\
\text { to uphold the values of the adolescent }\end{array}$ & $\begin{array}{l}\text { Religious values } \\
\text { Build trust }\end{array}$ \\
\hline Unclear/None & $\begin{array}{l}\text { The rationale itself does not indicate a clear } \\
\text { purpose }\end{array}$ & $\begin{array}{l}\text { That's how it is. } \\
\text { None }\end{array}$ \\
\hline
\end{tabular}

\begin{tabular}{|l|l|l|}
\hline Consequence type & Definition & Examples \\
\hline Verbal reprimand & $\begin{array}{l}\text { Any consequence with verbal consequences that do not } \\
\text { have other consequences }\end{array}$ & $\begin{array}{l}\text { A lecture } \\
\text { A talking-to } \\
\text { Yelling }\end{array}$ \\
\hline $\begin{array}{l}\text { Removal of privileges or } \\
\text { freedoms }\end{array}$ & $\begin{array}{l}\text { Any consequence where some privilege other than dating } \\
\text { is removed }\end{array}$ & $\begin{array}{l}\text { Grounding } \\
\text { Taking phone }\end{array}$ \\
\hline
\end{tabular}




\begin{tabular}{|l|l|l|}
\hline Dating restrictions & Any consequence that limits current or future dating & $\begin{array}{l}\text { Not allowed to } \\
\text { go }\end{array}$ \\
\hline Natural consequences & Only the natural consequences of the behavior are listed & $\begin{array}{l}\text { STDs } \\
\text { Pregnancy } \\
\text { Arrest } \\
\text { Physical Harm }\end{array}$ \\
\hline
\end{tabular}

Child Discomfort or Anxiety

\begin{tabular}{|c|c|c|}
\hline Score & Definition & Examples \\
\hline 1 & $\begin{array}{l}\text { No anxiety or discomfort - Child is active } \\
\text { with no visible or verbal signs or anxiety } \\
\text { or discomfort. }\end{array}$ & $\begin{array}{l}\text { Child confronts rules frequently. } \\
\text { Child maintains eye contact without visible signs } \\
\text { of anxiety such as fidgeting or nervous laughter. }\end{array}$ \\
\hline 2 & $\begin{array}{l}\text { Mild situational discomfort as evidenced } \\
\text { by either verbal or nonverbal behaviors. }\end{array}$ & $\begin{array}{l}\text { Child hesitates slightly around a single issue. } \\
\text { Child briefly displays some anxiety initially, but it } \\
\text { quickly subsides. }\end{array}$ \\
\hline 3 & $\begin{array}{l}\text { Moderate situational discomfort or anxiety, } \\
\text { or mild discomfort throughout. }\end{array}$ & $\begin{array}{l}\text { Child demonstrates strong hesitance or discomfort } \\
\text { discussing more personal issues such as sex. } \\
\text { Child seems mildy anxious or nervous throughout } \\
\text { as evidenced by nonverbal indicators, but is not } \\
\text { hindered verbally. }\end{array}$ \\
\hline 4 & $\begin{array}{l}\text { Strong situational discomfort or moderate } \\
\text { discomfort throughout the discussion. }\end{array}$ & $\begin{array}{l}\text { Child seems uncomfortable or anxious throughout } \\
\text { the discussion with some verbal inhibitions or } \\
\text { exclamations. } \\
\text { Child avoids speaking frequently, but shows only } \\
\text { mild nonverbal indicators of anxiety. }\end{array}$ \\
\hline 5 & $\begin{array}{l}\text { Strong discomfort as evidenced by strong } \\
\text { nonverbal indicators such as constant } \\
\text { fidgeting or, verbal exclamations of } \\
\text { anxiety }\end{array}$ & $\begin{array}{l}\text { Child does not speak frequently or at all, and } \\
\text { shows strong nonverbal indicators of anxiety. } \\
\text { Child makes verbal indications of anxiety with } \\
\text { moderate nonverbal indicators. }\end{array}$ \\
\hline
\end{tabular}

Nonverbal indicators include nervous laughter, blushing, avoiding eye-contact, inhibiting responses, avoiding speaking.

Child Questioning and Challenging

\begin{tabular}{|l|l|l|}
\hline Score & Definition & Examples \\
\hline 1 & Child accepts all rules without question. & No questions. \\
\hline 2 & $\begin{array}{l}\text { Child seeks mild clarification of a rule without } \\
\text { disagreement. }\end{array}$ & Is that a weeknight or weekend curfew? \\
\hline 3 & $\begin{array}{l}\text { Child seeks clarification multiple times } \\
\text { without challenging or challenges a rule and } \\
\text { quickly accepts. }\end{array}$ & $\begin{array}{l}\text { Child seeks clarification about curfew and } \\
\text { dating about dating age. } \\
\text { Child challenges a curfew time, but concedes } \\
\text { quickly without further challenge. }\end{array}$ \\
\hline 4 & Child challenges the same rule multiple times & Child challenges a curfew extension and when \\
\hline
\end{tabular}




\begin{tabular}{|l|l|l|}
\hline & $\begin{array}{l}\text { with acceptance. } \\
\text { Child challenges multiple rules but eventually } \\
\text { accepts. }\end{array}$ & $\begin{array}{l}\text { shut down says, "Mom says it could be later", } \\
\text { but eventually concedes. } \\
\text { Child challenges a curfew and a dating age. }\end{array}$ \\
\hline 5 & Child outwardly rejects one or more rules. & $\begin{array}{l}\text { Child constantly challenges and refuses to } \\
\text { agree with a rule. } \\
\text { Child refuses to follow the rule if it in place. }\end{array}$ \\
\hline
\end{tabular}

Child Engagement

\begin{tabular}{|c|c|c|}
\hline Score & Definition & Examples \\
\hline 1 & $\begin{array}{l}\text { Child is not engaged in any dialog with the } \\
\text { parent including an absence of nonverbal } \\
\text { acknowledgment }\end{array}$ & $\begin{array}{l}\text { Child makes no eye contact and does not seem } \\
\text { affected by the father presenting the rules. }\end{array}$ \\
\hline 2 & Child is minimally engaged. & $\begin{array}{l}\text { Child makes nonverbal acknowledgements and } \\
\text { makes only affirmative one-word responses, but } \\
\text { not necessarily attentive throughout. }\end{array}$ \\
\hline 3 & Child is moderately engaged. & $\begin{array}{l}\text { Child makes some meaningful contribution to } \\
\text { the conversation as evidenced by the use of } \\
\text { complete sentences, but is not necessarily } \\
\text { attentive throughout. } \\
\text { Child is attentive throughout, but does not } \\
\text { necessarily make a meaningful contribution to } \\
\text { the dialogue. }\end{array}$ \\
\hline 4 & $\begin{array}{l}\text { Child is thoroughly engaged but still allows } \\
\text { the father to lead the conversation. }\end{array}$ & $\begin{array}{l}\text { Child is engaged throughout and makes } \\
\text { meaningful contributions to the father's rules or } \\
\text { statements. }\end{array}$ \\
\hline 5 & $\begin{array}{l}\text { Child is thoroughly engaged and takes the } \\
\text { lead in the conversation at times. }\end{array}$ & $\begin{array}{l}\text { Child starts their own agenda for the } \\
\text { conversation outside of the rules or statements } \\
\text { that the father presents. }\end{array}$ \\
\hline
\end{tabular}

Paternal discomfort or anxiety

\begin{tabular}{|l|l|l|}
\hline Score & Definition & Examples \\
\hline 1 & No anxiety or discomfort. & Father presents rules without hesitation or pause. \\
\hline 2 & $\begin{array}{l}\text { Mild situational discomfort as evidenced } \\
\text { by either verbal or nonverbal behaviors. } \\
\text { Moderate situational discomfort or anxiety, } \\
\text { or mild discomfort throughout. }\end{array}$ & $\begin{array}{l}\text { Father displays a short pause when initiating a } \\
\text { discussion about sex or another personal issue. }\end{array}$ \\
\hline 3 & $\begin{array}{l}\text { Father demonstrates strong hesitance or } \\
\text { discomfort discussing more personal issues such } \\
\text { as sex. }\end{array}$ \\
\hline 4 & $\begin{array}{l}\text { Strong situational discomfort or moderate } \\
\text { discomfort throughout the discussion. }\end{array}$ & $\begin{array}{l}\text { Father seems mildy anxious or nervous } \\
\text { but is not hindered verbally other than potential } \\
\text { stuttering. }\end{array}$ \\
\hline $\begin{array}{l}\text { Father seems uncomfortable or anxious } \\
\text { throughout the discussion with many nonverbal } \\
\text { indicators. }\end{array}$ \\
\hline
\end{tabular}




\begin{tabular}{|c|c|c|}
\hline & & $\begin{array}{l}\text { Father seems hesitant or stutters throughout } \\
\text { presenting rules. }\end{array}$ \\
\hline 5 & $\begin{array}{l}\text { Strong discomfort as evidenced by strong } \\
\text { nonverbal indicators such as constant } \\
\text { fidgeting or, verbal exclamations of } \\
\text { anxiety }\end{array}$ & $\begin{array}{l}\text { Father shows strong nonverbal indicators of } \\
\text { anxiety. } \\
\text { Father makes verbal acknowledgements of } \\
\text { anxiety with moderate nonverbal indicators. }\end{array}$ \\
\hline
\end{tabular}

Paternal Checking-in

\begin{tabular}{|c|c|c|}
\hline Score & Definition & Example \\
\hline 1 & $\begin{array}{l}\text { Father does not prompt any response from the child } \\
\text { throughout the discussion. }\end{array}$ & $\begin{array}{l}\text { Father quickly transitions between } \\
\text { rules without stopping. }\end{array}$ \\
\hline 2 & $\begin{array}{l}\text { Father asks about understanding but never requests } \\
\text { feedback. (e.g. closed-ended questions) }\end{array}$ & $\begin{array}{l}\text { Do you understand? } \\
\text { You knew that right? }\end{array}$ \\
\hline 3 & $\begin{array}{l}\text { Father requests feedback, but only after the discussion. } \\
\text { Checking in about understanding may or may not be } \\
\text { present. }\end{array}$ & Any questions about any of those? \\
\hline 4 & $\begin{array}{l}\text { Father prompts or requests feedback in regard rules or } \\
\text { asks for the child to demonstrate understanding } \\
\text { throughout. Or, father checks in after each rule as to } \\
\text { whether the child accepts the rule. }\end{array}$ & $\begin{array}{l}\text { Multiple requests for feedback or } \\
\text { acceptance. }\end{array}$ \\
\hline 5 & $\begin{array}{l}\text { Father requests feedback regularly and requires at least } \\
\text { one thorough response to a rule. }\end{array}$ & $\begin{array}{l}\text { Father requires the child to respond in } \\
\text { detail to one or more rule. }\end{array}$ \\
\hline
\end{tabular}

Flexibility with rules

\begin{tabular}{|l|l|l|}
\hline Score & Definition & Example \\
\hline 1 & $\begin{array}{l}\text { Father is unwilling to change rules even in the face of } \\
\text { disagreement from child. }\end{array}$ & $\begin{array}{l}\text { "No your curfew is 10:00. No } \\
\text { questions." }\end{array}$ \\
\hline 2 & $\begin{array}{l}\text { No evidence of flexibility without a challenge from the } \\
\text { child (e.g. no opportunity to demonstrate flexibility to } \\
\text { warrant a 1) }\end{array}$ & $\begin{array}{l}\text { Absence of a challenge, but no } \\
\text { flexibility expressed. }\end{array}$ \\
\hline 3 & $\begin{array}{l}\text { Father agrees to consider modifying a rule but does not } \\
\text { do so during the discussion. }\end{array}$ & $\begin{array}{l}\text { We can discuss this with your } \\
\text { mother... }\end{array}$ \\
\hline 4 & $\begin{array}{l}\text { Father expresses that a rule can be modified after } \\
\text { disagreement from the child. }\end{array}$ & $\begin{array}{l}\text { OK. I would be OK with you dating } \\
\text { at 17 instead of 18. }\end{array}$ \\
\hline 5 & $\begin{array}{l}\text { Father describes a rule as flexible without prompting. } \\
\text { wou curfew will extend over time or } \\
\text { we can discuss this more later. }\end{array}$ \\
\hline
\end{tabular}




\section{CURRICULUM VITA}

\section{Chad S. Brice, M.S.}

December 19, 2011

Home: P.O. Box 1682

Davidosn, NC 28036

(919) 923-2802

Chad.brice@gmail.com

\section{Education}

West Virginia University, APA-Accredited

Morgantown, West Virginia

Degree: Candidate for Ph.D. in Psychology (anticipated May 2012)

Major: Clinical Child Psychology, Developmental Specialization

Dissertation Title: Dating Anxiety and Paternal Dating Rules (Proposed October 16, 2009)

Dissertation Chair: Tracy L. Morris, Ph.D.

West Virginia University, APA-Accredited

Morgantown, West Virginia

Degree: M.S., May 2007

Major: Clinical Child Psychology

Thesis Title: Behavioral Inhibition and Behavioral Activation in College Students: The effects of aversive control (Defended December 8, 2008)

Thesis Chair: Tracy L. Morris, Ph.D.

University of North Carolina at Chapel Hill

Chapel, Hill, NC

Degree: $\quad$ B.A., July 2003

Major: Psychology

\section{Teaching Experience}

2010 Graduate Teaching Instructor - Poverty and Development, West Virginia University

Supervisor: Tracy Morris Ph.D.

2008-2009 Graduate Teaching Assistant - Clinical Interviewing, West Virginia University

Supervisor: Elisa Krackow Ph.D. (Fall 2008)

Supervisor: Barry Edelstein Ph.D. (Fall 2009)

2008-2009 Undergraduate Research Supervision, West Virginia University

- Supervised data collection (Spring 2008 - Fall 2008)

- Supervised honors thesis (Spring 2009)

2006-2007 Graduate Teaching Instructor - Introduction to Psychology, West Virginia University 
Supervisor: Cheryl McNeil, Ph.D. and Claire St. Peter-Pipkin, Ph.D. (Fall 2006 Spring 2007)

\section{Clinical Experiences}

August 2010 - August 2011 Casa Pacifica Center for Children and Families Supervisors: Melissa Edwards, Psy.D., Lisa Cohen, Ph.D., and Laureen Worden, Ph.D.

- Provide individual therapy, family therapy, case management, and lead a multidisciplinary team for children and adolescents attending a non-public day-treatment school (NPS).

- Provide Parent-Child Interaction Therapy (PCIT) to families who qualify for MediCal or are involved in the Children and Family Services (CFS) system.

- Co-lead an Aggression Replacement Therapy (ART) group for children and adolescents living in a residential treatment facility (RTF).

- Conduct psychological and psychosocial assessments for children and adolescents attending an NPS, or living in an RTF or crisis shelter.

July 2008-July 2010

Washington County Children and Youth Services, Washington, Pennsylvania

Supervisor: Michael Crabtree Ph.D.

- Conduct court-ordered and caseworker referred mental health evaluations for children and parents involved with child welfare.

- Interact with caseworkers, court-system, and community treatment providers to make treatment recommendations.

Marital Therapy Workshop, Co-facilitator, West Virginia University

Supervisor: Tracy L. Morris, Ph.D.

- Co-led a six-hour workshop for engaged and newly married couples, based on the empirical work of John Gottman, Ph.D., to enhance foundational relationship skills.

- $\quad$ Provided individual feedback to couples on current skill sets and potential problem areas based on observations and self-report measures completed.

May 2007-July 2008

Graduate Assistant, Quin Curtis Center, West Virginia University

Supervisor: William Fremouw Ph.D.

- Responsibilities included screening potential clients, conducting intakes and evaluations, and managing quality assurance checks.

August 2007-July 2008

Quin Curtis Center, Adolescent Clinical Team, West Virginia University Supervisor: Steven Branstetter, Ph.D.

- Conducted therapy and parent-training for adolescents with a range of clinical presentations, and ADHD assessments 
August 2006-August 2008
Quin Curtis Center, Parent-Child Interaction Therapy Team (PCIT), West Virginia University Supervisor: Cheryl McNeil, Ph.D.

Conducted PCIT with children between ages 3-7 and their parents for oppositional behaviors. Conducted exposure therapy with PCIT parenting components for a young child with an anxiety disorder.

\section{Publications}

Stevens, S. B., Brice, C. S., Ale, C. M., \& Morris, T. L. (2010). Substance use and sexual activity in foster and community youth. Manuscript submitted for publication in Child Welfare.

Stevens, S. B., Brice, C. S., Ale, C. M., \& Morris, T. L. (2010). Do depression and anxiety predict substance use and sexual activity in adolescents? Manuscript submitted for publication in Youth and Society.

Ale, C. M., Chorney, D. C., Brice, C., \& Morris, T. L. (2009). Facial Affect Recognition and Social Anxiety in Preschool Children, Early Child Development and Care. Advance online publication. doi: 10.1080/03004430903059318

\section{Presentations}

Stevens, S. B., Brice, C., Ale, C., \& Morris, T. L. (2010). Substance use and sexual activity in foster and community youth. Paper presented at the annual convention of the Southeastern Psychological Association, Chattanooga, TN.

Stevens, S. B., Brice, C., Ale, C., \& Morris, T. L. (2010). Do Anxiety and Depression Predict Substance Use and Sexual Activity? Paper presented at the annual convention of the Southeastern Psychological Association, Chattanooga, TN.

Ale, C., Chorney, D., Brice, C., \& Morris, T. Social Anxiety and Facial Affect Recognition in Preschool Children. Poster Presentation. Association for Behavioral and Cognitive Therapies. November 2008. Orlando, FL.

Brice, C., Jones, A., Ale, C., Drescher, C., \& Morris, T. Actions Speak Louder than Words: An Analysis of ABCT Poster Methodology. Poster Presentation. Association for Behavioral and Cognitive Therapies. November 2008. Orlando, FL.

Moore, P., Garcia, A., Gonzalez, A., Brice, C., Thienemann, M., Huffman, L. Physiological Arousal in Parent-Child Interaction Paradigms Commonly Used in Anxiety Research. Poster Presentation. Society for Research in Child Development. April 2005. Atlanta, GA. 


\section{Invited Presentations and Colloquia}

McCoy, K., \& Brice, C. (March, 2010) Parenting Evaluations: A Case of Alleged Physical Abuse. Case Presentation to the Clinical Psychology Programs, West Virginia University, Morgantown, WV.

Brice, C. (December, 2009). Is That Medically Necessary? A Story of Third-Party Payers. Case Presentation to the Clinical Psychology Programs, West Virginia University, Morgantown, WV.

Brice, C., \& Tempel, A. (November, 2008) Early Childhood Anxiety: Exposing parents to exposures. Case Presentation to the Clinical Psychology Programs, West Virginia University, Morgantown, WV.

\section{Employment}

2003-2006

\section{Research Assistant for Clinical Trials Department of Psychiatry, Duke University Medical Center Durham, North Carolina}

Supervisors: John March, MD, MPH, Karen Wells, Ph.D., Phoebe Moore, Ph.D., Scott Compton, Ph.D., and David Goldston, Ph.D.

Duke Coping Power Program (NIDA and CSAP-funded)

Treatment in Pediatric Obsessive-Compulsive Disorder (NIMH-5R01MH055121)

Obsessive Compulsive Disorder Imaging Pilot

Child and Adolescent Anxiety Multisite Study (CAMS) (NIMH-2U01MH064107)

Treatment of Adolescent Suicide Attempters (TASA) (NIMH - NCT00080158)

Relapse Prevention for Suicidal Dually Diagnosed Youth (NIMH - 1R34MH067904-01A1)

Responsibilities: conducting in-home Computerized Diagnostic Interview Schedule for Children (C-DISC), collecting self-report data, attrition management, collecting school data and court records, consenting subjects, supervising a team of undergraduate research assistants, recruitment, cleaning data, facilitating cross-site collaboration, creating case report forms, screening patients, preserving the blind, screening patients for MRI scans, administering Peabody Picture Vocabulary Test (PPVT), conducting urine drug screens, and assisting in grant and IRB submissions.

2002-2003 Undergraduate Research Assistant, Duke Coping Power Program Department of Psychiatry, Duke University Medical Center, Durham, North Carolina Supervisor: Karen Wells

Responsibilities: conducting in-home Computerized Diagnostic Interview Schedule for Children (C-DISC), collecting self-report data, tracking participants for longitudinal research

\section{Service}

WVU Clinical Child Training Committee 2007-2008

WVU Psychology Department Wellness Committee 2007-2008

WVU Graduate Training Committee 2008-2009 
WVU APAGS Campus Representative 2008-2009

WVU Full Faculty Representative 2009-2010

\section{Memberships}

Society of Clinical Child and Adolescent Psychology - APA, Division 53

Association for Behavior and Cognitive Therapies (ABCT) 